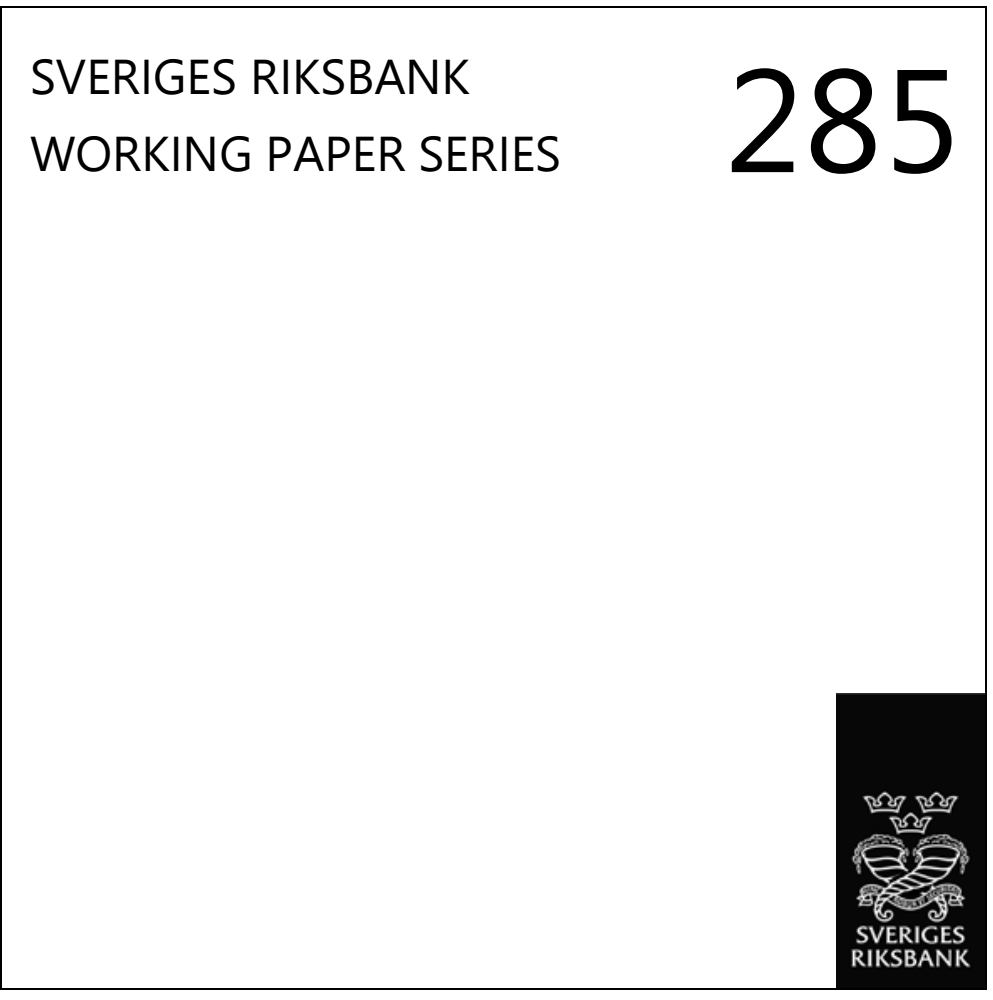

\title{
Incompatible European Partners? \\ Cultural Predispositions and Household Financial Behavior
}

Michael Haliassos, Thomas Jansson and Yigitcan Karabulut

June 2014 (Updated January 2015) 


\section{WORKING PAPERS ARE OBTAINABLE FROM}

Sveriges Riksbank • Information Riksbank • SE-103 37 Stockholm

Fax international: +4687870526

Telephone international: +4687870100

E-mail: info@riksbank.se

The Working Paper series presents reports on matters in the sphere of activities of the Riksbank that are considered to be of interest to a wider public.

The papers are to be regarded as reports on ongoing studies and the authors will be pleased to receive comments.

The views expressed in Working Papers are solely the responsibility of the authors and should not to be interpreted as reflecting the views of the Executive Board of Sveriges Riksbank. 


\title{
Incompatible European Partners? Cultural Predispositions and Household Financial Behavior ${ }^{\#}$
}

\author{
Michael Haliassos \\ Goethe University Frankfurt, CFS, CEPR \\ Thomas Jansson \\ Sveriges Riksbank \\ Yigitcan Karabulut \\ Rotterdam School of Management, Erasmus University
Sveriges Riksbank Working Paper Series
No. 285
January 2015

\begin{abstract}
The Eurozone fiscal crisis has created pressure for institutional harmonization, but skeptics argue that cultural predispositions can prevent convergence in behavior. Our paper derives a robust cultural classification of European countries and utilizes unique data on natives and immigrants. Classification based on genetic distance or on Hofstede's cultural dimensions fails to identify a single 'southern' culture but points to a 'northern' culture. Our findings support the relevance of cultural predispositions for financial behavior; and convergence of behavior over time in the face of common institutions, even for countries with great cultural distance from the country that created those institutions.
\end{abstract}

JEL Classification: G11, E21

Keywords: Household Portfolios, Household Finance, Cultural Influences on Economic Behavior

\footnotetext{
\# We thank Marieke Bos, Enrico Spolaore, participants in the December 2013 conference of Norges Bank on Household Finance, the 2014 International Pensions Conference of NETSPAR, the 2014 Research in Behavioral Finance Workshop, and in the 2014 Conference on Research in Economic Theory and Econometrics, as well as participants in the research seminars at the University of Luxembourg, the University of St. Gallen, Lund University, Maastricht University, and the Household Finances and Consumption Network of the ECB, for their constructive comments. Per Sidén provided excellent research assistance. We acknowledge support from the German Research Foundation (DFG), from a NETSPAR competitive grant, and from the Center of Excellence SAFE at Goethe University Frankfurt. The views described in this paper are the authors' own and do not necessarily reflect those of the Sveriges Riksbank. Email addresses: Haliassos@wiwi.uni-frankfurt.de, thomas.jansson@riksbank.se, karabulut@rsm.nl.
} 


\section{Introduction}

The recent Eurozone crisis has inspired efforts and pressure for reforms contributing to the harmonization of institutions and policies across member countries. In the face of considerable cultural diversity in Europe, however, one wonders whether sizeable differences in economic behavior, reflecting cultural predispositions, could still exist and persist even in the face of common institutions and policies. If this is the case, particularly in the sphere of financial behavior, institutional harmonization may not be the right approach: differential institutions and policies may be necessary to neutralize cultural predispositions and harmonize economic behavior across a culturally diverse set of countries, to the extent necessary for the normal functioning of the European Union and adherence to its treaties.

As emphasized in a recent working paper by Alesina and Giuliano, ${ }^{1}$ there is normally a twoway interaction between culture and institutions: an ethnic or cultural group chooses certain institutions, and in turn these institutions tend to preserve and promote the culture among future generations. Current attempts to impose on some European countries (in the South) institutions different from those that emerged from their own culture, in the hope that they will influence and harmonize behavior across North and South clearly interfere with this normal interaction and pose a question of a different nature. What happens to behavior (and ultimately culture) when institutions that did not emerge from that culture are maintained (through international coordination, monitoring, and conditionality)? Can we expect behavior to differ initially, depending on cultural predisposition, but then converge over time?

This paper focuses on an important aspect of economic behavior, household financial behavior, which played an important role in some (though not all) of the recent crises and which could contribute to future crises. It asks whether there are sizeable differences in financial behavior linked to cultural predispositions and whether these differences are likely to persist in the face of a common set of relevant institutions and policies that did not arise from the original culture but is accepted by households of different cultural predispositions.

Our approach is to compare the financial behavior of households from different cultural backgrounds who live in the same country and thus face a common institutional environment that did not arise from their own culture. We utilize data from the Longitudinal Individual Database (LINDA), a data set of unmatched quality and precision, on natives and immigrants from different European countries that have been exposed to the Swedish institutional and policy environment. We first group immigrants according to cultural background in a robust way, following two independent approaches: one based on genetic distance (Cavalli-Sforza, Menozzi,

\footnotetext{
${ }^{1}$ See Alesina and Giuliano (2014) for a comprehensive overview of the literature on the relationship between culture and institutions.
} 
and Piazza, 1994) and the other based on Hofstede's (1980) cultural dimensions. We then adopt econometric methodology, which only recently has been applied to household financial behavior and is novel to immigrant studies, to study differences in financial behavior and immigrants' resilience to exposure to common (host country) versus original (home country) institutions. We also study the role of exposure to formal versus informal institutions in the host country. This is because exposure to informal institutions is unlikely to be a feature of an EU harmonization experiment transplanting international best practices.

Recent research finds considerable variation in household financial behavior across countries, even among households of similar observable characteristics (Christelis, Georgarakos, Haliassos, 2013). Such differences can be attributed either to relevant institutions, markets, and constraints or to culture, with unclear divisions among them. Using LINDA, we can observe a wide range of household characteristics and assets (financial and real) and debts (both collateralized and uncollateralized), along with the national origin of each single person or partner living in Sweden and whether those people were born in Sweden or elsewhere. By studying native and immigrant behavior in a single country, we are in much better position to distinguish the role of cultural predispositions from that of institutions and policy environment.

We first devote considerable effort to defining the cultural groups of European countries in a robust way and independently of household financial behavior. We follow two independent approaches. In our benchmark results, which are presented in the paper, we use a measure of "genetic distance" of (dominant) populations in each European country (Cavalli-Sforza, Menozzi, and Piazza, 1994). Genetic distance measures are shown to capture the divergence in intergenerationally transmitted (biologically and/or culturally) traits such as norms, values, habits, and biases across populations (Spolaore and Wacziarg, 2009). Desmet et al. (2011) also document a close relationship between genetic distance and answers to the World Values Survey regarding norms, values, and cultural characteristics. An alternative approach we explore (in an Appendix available online) is the concept of cultural dimensions proposed by Hofstede (1980), based on IBM employees in different countries. We show that cultural groups are quite robust to both methods. Classification based on genetic distance or on Hofstede's cultural dimensions fails to identify a single 'southern' culture but points to 'northerners' as forming a cultural group.

Using these groups, we first document differences in asset and debt holdings between immigrants and their evolution over the length of our sample, from 1999 to 2007, using Northerners (other than native Swedes) as the base group for comparison. We then employ modern econometric methods of counterfactual analysis to decompose the observed differences into those arising out of differences in participation-relevant household characteristics (i.e., 
covariate effects) and unobserved characteristics faced by households with similar characteristics (i.e., coefficient effects). In Section 2, we discuss how our approach avoids some arbitrary restrictions incorporated into the existing literature using immigrant samples and provide a broader view of the link between culture and financial behavior.

Because all households in our sample work with the same institutions and are subject to the same legal practices, statistically significant coefficient effects are more directly attributable to cultural predispositions than if we were to compare the original populations. We then ask whether the estimated pattern of differences is a mere artifact of different lengths of time spent in Sweden by groups from different countries or whether it is linked to possible discriminatory practices of the financial sector as a result of being differently allocated in areas that exhibit more or less friendly attitudes to foreigners. Using LINDA data on the length of stay in Sweden, along with auxiliary data on attitudes towards immigrants recorded in different Swedish provinces, we are able to show that differences in financial behavior are present even after accounting for heterogeneous length of stay and possible discrimination by the financial sector.

We next turn to the issue of resilience of cultural predispositions to exposure to common institutions. We first conduct a probit analysis of participation by different culture groups, allowing for region and time fixed effects, to show that length of stay in Sweden and age at immigration are statistically significant for participation in stockholding, debt, and homeownership, with signs that imply smaller differences for people who moved at younger ages or were exposed longer to host-country institutions.

Further, we divide the immigrants in each country group into two subgroups based on their length of stay in Sweden: those above the median stay for their group and those below. We decompose the differences in asset participation rates between the immigrants in each of those subgroups and Swedes separately. This exercise shows that coefficient effects for those who stayed longer tend to be smaller than those who have had less exposure to Swedish institutions.

We next explore the role of exposure to original (home) institutions during an immigrant's working life. We find that those who moved before turning 18 exhibit smaller differences from Swedes but that those differences tend to be statistically significant even for the group that did not themselves choose to move to Sweden. Finally, we find that having Swedish citizenship is linked to greater closeness to Swedish financial behavior. This effect is suggestive but not causal because having Swedish citizenship may partially reflect a greater willingness to assimilate.

Our results on assimilation complement a broad literature on effects of institutions on culture (see Alesina and Giuliano, 2014, for an excellent review). Although we find convergence in behavior, we do not find that differences disappear completely with exposure to common 
institutions. This is consistent with recent studies (Guiso, Sapienza, and Zingales, 2004; Tabellini, 2010; and Alesina and Giuliano, 2013), which showed that national institutions do not eliminate regional variation in culture.

It can be argued that immigrants are more likely to feel close to the culture of the host country and to want to adjust to host-country behavior than are those who never chose to immigrate. Although this works against finding significant differences between immigrants and natives, it could result in an overestimate of the degree to which cultural predispositions can be overcome by exogenously imposed exposure to common institutions. We take a number of steps to handle this and other issues, and we discuss them in Section 7, but we note here that our policy implications refer to institutional harmonization that is accepted by the population and are silent on what would happen if it were forced upon it.

Section 2 discusses the existing literature and our methodological contribution. Section 3 describes the data. Section 4 presents key elements of the method for classifying countries into culture groups. Section 5 documents differences in financial behavior among immigrant groups and then estimates the differences controlling for household characteristics, length of stay, and regional attitudes towards immigrants. Section 6 studies the degree of resilience of cultural influences on financial practices to a common institutional environment; its dependence on whether the household was exposed to the original (home) institutions during its active economic life; and whether the head of household was intensely exposed to informal Swedish institutions through a Swedish-born partner with Swedish citizenship. Section 7 discusses robustness and limitations, while section 8 concludes. Online Appendix (O.A.) A describes how genetic distance is used to derive the cultural groups used in the main body of the paper, O.A. B describes the data; O.A. C presents the estimates of probit regressions for participation in each asset class; O.A. D provides supplementary tables and figures; O.A. E presents the results using Swedish households as the base group; and Online Appendix F presents the results using the Hofstede dimensions for robustness.

\section{Existing Literature and Empirical Approaches}

In recent years, the complex role of culture in explaining cross-country variations in economic outcomes has received considerable attention. Following the conceptual framework outlined in Guiso, Sapienza, and Zingales (2006), culture can be subdivided into slow-moving components linked to religion and ethnicity and the fast-moving components that are shaped by 
social interactions, the latter of which are not our focus in this paper. ${ }^{2}$ The slow-moving components can influence a range of economic outcomes, several of which have been explored in existing works.

A number of studies have linked economic outcomes directly to culture, represented either by religion/ethnicity or by the nature of the same outcome in the home country (e.g., stockownership in the host country regressed on stockownership in the home country of each immigrant) or by some key institutional feature in the country of origin (e.g., investor protection).

The first specification used by a number of studies employing household-level or individual data is essentially of the form

$$
Z_{i j}=\alpha+\lambda^{\prime} X_{i}+\sum_{k} \beta_{k} D_{i k}+\varepsilon_{i j}
$$

where $Z_{i j}$ is the outcome variable (for household $i$ with country of origin $j$ ), $X$ represents a vector of characteristics, and $D$ is a dummy variable showing the country of origin $j$ of household $i$. The second is of the form

$$
Z_{i j}=\beta_{0}+\beta_{1}^{\prime} X_{i}+\beta_{2} \tilde{Z}_{j}+\varepsilon_{i j}
$$

where the variable $\tilde{Z}_{j}$ represents the average value of the outcome variable in the country of origin. Finally, the third specification is of the form

$$
Z_{i j}=\beta_{0}+\beta_{1}^{\prime} X_{i}+\beta_{2} S_{j}+\varepsilon_{i j}
$$

where $S_{j}$ represents some institutional feature of the home country (e.g., investor protection in the country of origin).

This significant literature has explored a number of different outcomes either at the country or at the individual level, including household saving rates (Caroll, Rhee, and Rhee, 1994), ${ }^{3}$ use of basic financial instruments (Guiso, Sapienza, and Zingales, 2004; Osili and Paulson, 2008a), stock market participation (Osili and Paulson, 2008b), women's work and fertility behavior (Fernandez and Fogli, 2006, 2009; Alesina and Giuliano, 2010), international trade and investments (Guiso, Sapienza, and Zingales, 2009), regional economic development

\footnotetext{
${ }^{2}$ For the effects of social interactions on financial behavior, see Georgarakos, Haliassos, and Pasini (2014) and references to significant papers therein.

${ }^{3}$ Using individual-level data on immigrants to Canada, who potentially differ in their social preferences and beliefs, Carroll, Rhee, and Rhee (1994) analyze whether households' country of origin correlates with their saving behavior. The authors find no significant cross-country differences in the overall saving patterns among immigrants from different areas. They show that recent immigrants to Canada tend to save less than natives, and that their saving behavior seems to converge with that of natives over time.
} 
(Tabellini, 2010), and individual tax morale, i.e., the willingness to pay taxes (Kountouris and Remoundou, 2013). ${ }^{4}$

The channel through which slow-moving aspects of culture influence such economic outcomes is through preferences and beliefs (priors) and through political and institutional features. Several authors have provided evidence for the presence of such an operative culture channel. The literature typically regresses economic outcomes on household or country characteristics as appropriate for the data at hand and on a measure of preferences or beliefs instrumented by ethnicity or religion. ${ }^{5}$ Other papers separate the channel into two different parts: from religion/ethnicity to preferences and beliefs, such as trust or preferences for redistribution; and from the latter to economic outcomes. ${ }^{6}$

Obviously, regressions of outcomes directly on ethnicity, on the nature of the outcome in each immigrant's home country or on a particular institutional feature of the home country are less informative about the nature of the channel through which culture influences economic outcomes than are studies that explore a particular channel. Conversely, the latter confront the problem that religion or ethnicity are likely to influence economic outcomes through a variety of channels beyond that specified in each paper, for which it may not be possible to control.

As illustrated by (1), (2), and (3), existing approaches typically focus on the coefficient of the "culture variable" and assume, for reasons of parsimonious modeling, that coefficients are common across cultures, including natives (with the obvious exception of the dummy coefficients $\beta_{k}$ in equation (1) representing shifts in the relationship), are constant over time, and are invariant to the length of experience that immigrants have had in the host or home country.

The econometric approach we follow in this paper, described in section 5.2.1 below, allows an association of given household characteristics with different economic behavior depending on a household's cultural background and on the length and intensity of its exposure to home and host country institutions and polices. Indeed, our analysis, based on constructing

\footnotetext{
${ }^{4}$ Borjas (2002) documents that immigrants' homeownership rates seem to vary significantly by country of origin, although he does not draw an explicit link to cultural or institutional factors. Bogaard and Pirinsky (2011) find that U.S. residents with ancestors from countries with higher financial development are more likely to be homeowners, to work in the financial industry, and to take on more debt. Oyelere and Belton (2012) show that immigrants from developed countries have higher self-employment probabilities than immigrants from developing countries, even though self-employment rates in developed countries are lower.

${ }^{5}$ Guiso, Sapienza and Zingales (GSZ 2003, 2006) show that thriftiness is influenced by religious denomination and use populations' religious composition as an instrument for the proportion of people who believe that teaching thriftiness is important. A regression of national saving rates on country characteristics and on the instrumented preference for teaching thriftiness yields suggestive but inconclusive results. GSZ (2003) finds an effect of religion on trust, controlling for demographics and country-fixed effects and using instruments relating to whether the respondent still practices or whether he or she was educated after opening religious dialog.

${ }^{6}$ GSZ finds an effect of ethnic origin on trust in the U.S. data (2006) and establishes a link between trust and stock market participation (2008). The work of GSZ (2006), Alesina and Giuliano (2011), and Luttmer and Singhai (2011) suggests that individual preferences for redistribution are affected by culture and in turn, can influence the relative importance of regressive to progressive taxes in a country (outcome).
} 
counterfactual probabilities of participation and computing total "coefficient effects", suggests that such broader differences exist, are statistically significant, and are quite persistent but also subject to change following exposure to particular sets of institutions and policies, consistent with the idea that there are slow-moving aspects of culture that influence economic outcomes.

\section{The Micro Data}

We use LINDA provided by Statistics Sweden for the observation period from 1999 to 2007. LINDA consists of an annual cross-sectional sample of approximately 300,000 individuals, or approximately $3 \%$ of the entire Swedish population, and an annual immigration sample of approximately 200,000 individuals, or approximately $20 \%$ of all immigrants in Sweden. An individual is included in the immigrant sample if he/she was born outside Sweden. Selected individuals and their family members are tracked over the years. The sampling procedure ensures that the panel is representative of the relevant population as a whole and that each annual cohort is cross-sectionally representative. The database provides detailed and highly accurate information on the financial and demographic characteristics of each sampled household. Furthermore, the data include detailed information on household assets (financial and real) and debts (both collateralized and uncollateralized) for the entire sample period, along with the national origin of each single person or partner in a marriage and whether they were born in Sweden or elsewhere.

When constructing the sample, we adopt the following procedure. First, we begin with all households in both the regular and immigrant LINDA databases. In LINDA, two adults are defined as in the same household in a given year if they are either married or legal partners or if they live together and have children in common (Betermier et al., 2012). To identify the reference person (head of household) in a given household, we follow the Canberra definition. ${ }^{7}$ We then use the socioeconomic characteristics of head of household when defining household controls, which include age, gender, work status (unemployed, retired, student, employed), marital status, educational level (high school graduate, college graduate), separate indicator variables of whether the head of household works in the financial sector or for the government, municipality of residence, and country of birth. We aggregate the asset and debt holdings along with the income at the household level.

\footnotetext{
${ }^{7}$ The Canberra definition of the reference person in a household applies the following rule in the order provided: "one of the partners in a registered or de facto marriage, with children; one of the partners in a registered or de facto marriage, without dependent children; a lone parent with dependent children; the person with the highest income; the eldest person". See Canberra Group Handbook on Household Income and Statistics (2011) for more details.
} 
In our analysis, we restrict our attention to those (both Swedish and immigrant) households that existed for the entire sample period from 1999 to 2007, and in which the head couple (or the single head member) remained the same, resulting in a strongly balanced panel. Moreover, we exclude from the sample those observations in which the head of household is less than 18 years of age, or the annual disposable household income is less than 10,000 SEK. ${ }^{8}$ Finally, we restrict our immigrant sample to individuals born in a European country. ${ }^{9}$

We follow a conservative approach when we define a household as native (i.e., Swedish). In particular, in each year, if the household head and spouse (if any) were born in Sweden and both have Swedish citizenship, the household is regarded as native. If a household does not fulfill these criteria, we exclude it from the sample. Conversely, a household is defined as immigrant if the head of household was born outside Sweden. In other words, we do not impose any restrictions on the birth country or citizenship status of the remaining household members.

Overall, in the final sample, we have 143,217 households in the Swedish sample, and 72,740 households in the European immigrants sample for each year from 1999 to 2007, which results in approximately 1.94 million household-year observations.

\section{Construction of the Cultural Groups}

Here we describe how culture groups were obtained. We first describe the concept of genetic distance and explain its link to cultural distance. We derive country groupings based on this concept in two ways: first, based on the genetic distance of immigrants from the baseline Swedish population; second, based on genetic distance across all country pairs. We then form cultural groups based on an independently derived, time-honored set of measures, i.e., the cultural dimensions proposed by social psychologist Geert Hofstede (1980), and show that our baseline grouping based on genetic distance is quite consistent with the grouping based on the Hofstede cultural dimensions. In Online Appendix F, we report detailed results on household financial behavior using the Hofstede-based alternative, as a robustness exercise. Online Appendix A contains details on construction of cultural groups based on genetic distance.

\subsection{Genetic Distance as a Measure of Cultural Distance}

Genes are the hereditary factors responsible for traits, and DNA is the hereditary material

\footnotetext{
${ }^{8}$ The reason for excluding households with an annual household disposable income of less than 10,000 SEK is that these observations most likely represent erroneous data. We also exclude from the sample households with missing information on education and wealth and with multiple birth countries. In addition, there are 2,375 immigrant households that appear both in the regular and immigrant sample. We also drop those "repeated" observations from the sample.

${ }^{9}$ We use a geographical definition of Europe, which requires a country to have at least part of its territory in Europe.
} 
of all life forms (except for some types of viruses). Organisms with similar DNA sequences are descended from a common ancestor. A gene is commonly defined as a sequence of DNA that encodes a protein. An allele is one of two or more versions of a gene. (For example, the specific gene for eye color is of different types, such as brown eye color and blue eye color, which are called alleles.) An allele is selectively neutral if it does not provide any advantage in the naturalselection process to the individual who has it.

Genetic distance between two populations measures the time that has passed since two populations existed as a single population. Smaller genetic distances imply that the populations share a recent common ancestor. Technically, genetic distance measures the difference in allelic frequencies across different populations, in which the considered alleles are selectively neutral. As Spolaore and Wacziarg (2009) argue, "an intuitive analogue is relatedness between individuals: two siblings are more closely related than two cousins because they share more recent common ancestors - their parents rather than their grandparents". Accordingly, populations with similar allelic frequencies are more likely to share similar traits and characteristics, which are transmitted across generations both biologically and culturally. Thus, genetic distance reflects divergence in beliefs, customs, habits, biases, conventions, etc., which are transmitted across generations with high persistence (Spolaore and Wacziarg, 2009).

How good a proxy is genetic distance for cultural distance? Desmet et al. (2011) provide empirical support that validates genetic distance as a proxy for cultural heterogeneity, showing a strong and robust correlation between cultural distances based on answers to the World Values Survey (WVS) and genetic distances across European populations. ${ }^{10}$ They also show that the correlation between genetic distance and cultural distance based on the WVS remains positive and significant even after controlling for languages and geography. Support from a different angle is provided by this paper, which shows that country groups based on genetic distance are quite similar to those generated by reference to Hofstede's cultural dimensions (see below and Online Appendix F). ${ }^{11}$

\subsection{The Hofstede Cultural Dimensions}

An alternative way to form country groups based on culture draws on the path-breaking work of social psychologist Geert Hofstede, who introduced the notion of "cultural dimensions" in his 1980 book Culture's Consequences. Those dimensions were derived from a

\footnotetext{
${ }^{10}$ In particular, Desmet et al. (2011) show that European populations that share a recent common ancestor (i.e., are genetically closer) provide more similar answers to a set of 430 questions about norms, values, and cultural characteristics that are included in the 2005 WVS.

${ }^{11}$ When analyzing the relationship between trust and economic exchange, Guiso, Sapienza, and Zingales (2009) also use genetic distance as an instrument for bilateral trust.
} 
statistical analysis of two databases containing answers to survey questions on attitudes: one of matched IBM employee samples from 40 countries collected in the period 1967-73; and the other (on a subset of questions) of Hofstede's executive students from 15 countries. Systematic differences between nations referred to "values", defined as broad preferences for one state of affairs over others.

Hofstede originally proposed four cultural dimensions (to which two more were later added), and we confine our attention to those original four for reasons of data availability and comparability to the country set covered by the genetic distance measures. These dimensions are as follows: the Power Distance Index, which captures the extent to which the less powerful accept and expect that power is distributed unequally; Individualism, which captures the extent to which ties between individuals are loose and everyone is expected to fend for him- or herself; Masculinity, which captures the (absolute and relative) degree of competitiveness and assertiveness between men and women, with greater variations across countries being observed among men and much smaller variations among women; and Uncertainty Avoidance, which refers to the attitudes of different countries towards uncertainty and ambiguity. Recent studies have confirmed the relevance of Hofstede's cultural dimensions to financial behavior. ${ }^{12}$

For groupings according to Hofstede's cultural dimensions, we use the four original proposed dimensions, for which we have data for almost all of the countries covered under the alternative genetic distance measure. We first normalize each dimension so that it has a mean of zero and a standard deviation of one across all countries. We then calculate the Euclidean distance between each pair of countries based on all four dimensions.

\subsection{Cultural Country Groups in Europe}

We use a geographical definition of Europe, which requires a country to have at least part of its territory in Europe. This implies that we include Turkey, the Russian Federation, Belarus, and Ukraine in our analysis. We must exclude from the sample the following European countries because data on genetic distance are not available for them: Albania, Andorra, Lichtenstein, San Marino, Monaco, and Vatican City. Because the data contain some immigrants from countries that no longer exist, we merge immigrants from the following countries:

\footnotetext{
${ }^{12}$ For example, Chui, Titman, and Wei (2010) examine how cultural differences are linked to cross-country differences in investor behavior. More specifically, they use Hofstede's (1980) individualism index to measure cultural differences across countries, and show that the magnitude of momentum profits, trading volume, and volatility in the stock market are significantly higher in countries with more individualistic cultures. At the country level, Siegel, Licht, and Schwartz (2011) show that cross-country differences in culture, as measured by egalitarianism distance, have significant effects on cross-border flows of equity and bond issuance, syndicated loans, and mergers and acquisitions.
} 
- Slovakia, Czech Republic, and the former Czechoslovakia are merged under "Czechoslovakia";

- The former Socialist Federal Republic of Yugoslavia, Bosnia and Herzegovina, Croatia, the Former Yugoslav Republic of Macedonia, former Serbia and Montenegro, Serbia, Montenegro, and Slovenia are merged under "Yugoslavia";

- Russian Federation and the former Union of Soviet Socialist Republics are referred to as "Russia"; and

- The Federal Republic of Germany and the former German Democratic Republic are referred to as "Germany".

In forming cultural country groups, we must make three choices. The first relates to the measure of cultural distance: we consider genetic distance versus distance based on Hofstede's cultural dimensions. The second, relevant to the genetic distance measure, regards the ethnic groups to be compared across each country pair: the dominant group (in the sense of plurality) within each country versus all ethnic groups with their respective population weights. Once the relevant measures of distance are constructed, the third choice concerns the method for forming country clusters: we consider the ruler method versus the inconsistency method. We describe how we have implemented each of these alternatives for genetic distance and robustness across different choices in Online Appendix A.

Looking at Table 1, based on the genetic distance measure, perhaps the most striking fact is that although country groups are sometimes linked to geography (such as the Balkans, Finland and the Baltic countries, and several northern countries), in other cases it is particularly difficult to assign geographical names to the country groups that emerge. In terms of genetic distance, Italy is close to Russia and Spain is close to both Ireland and the UK. Turkey stands alone in terms of genetic distance. The Eurozone countries that have recently run into fiscal trouble span three different groups. This latter feature is also observed when we form country groups using Hofstede's dimensions (Table F.1). Moreover, in that four-group categorization, some "northern" countries (such as Germany and Austria) appear in the same cultural group as Italy and Ireland. These observations suggest caution in seeking a simple explanation for the pronounced tendency of some countries to run into budgetary problems linked to cultural predispositions, either measured by the recency of close interactions (genetic distance) or by the proximity of finance-relevant cultural attributes (Hofstede). 


\section{Differences in Participation Rates Among Cultural Groups}

\subsection{Differences in Raw Data}

Table 2 presents information on participation in stockholding, debt, and homeownership across the country groups derived from genetic distance. To give a summary indication of participation in an instrument and its duration within the sample period of 1999-2007, we report the percentage of relevant (household, year) pairs that record participation in each country group.

Our measure of stockholding includes both direct and indirect stockholding but excludes stocks held through retirement accounts. ${ }^{13}$ We see that Swedish non-immigrant households (called "Swedish" from now on) exhibit high and persistent participation (73\%) compared to all immigrant groups. We find some variation across immigrant groups, but the most striking finding is the particularly low participation rates in the Balkan group. Later, it will be important to explore whether this difference is linked to underlying characteristics of Balkan immigrants and how long they have been in Sweden or whether it represents a genuine difference in stockholding behavior for given relevant household characteristics.

Participation in all types of debt taken together (except for student loans) is even more pronounced ( $80 \%$ for Swedish households), with Balkans now closest to the indigenous population and others below the $70 \%$ mark. Balkan and Turkish immigrants exhibit the lowest homeownership rates by far, less than half of the $73 \%$ recorded for Swedes, whereas between half and two-thirds of the other country groups observed show homeownership.

Overall, the recorded participation among Swedish households is higher than that of all immigrant groups both in assets and in debts. Below, we explore possible reasons for immigrants' lower participation and for the variations across home-country groups: immigrants' inferior economic position, possible discrimination against immigrants in the asset markets, and a likely shorter horizon among immigrants who plan to go back to their home countries and therefore choose not to participate extensively in assets or debts in Sweden (while possibly owning assets or debts in their home countries).

\subsection{Differences in Participation Rates Controlling for Characteristics}

\subsubsection{The Distinction between Covariate and Coefficient Effects}

Observed differences in participation rates can be decomposed into two components: ${ }^{14}$ one, arising from differences in participation-relevant characteristics, is attributed to "covariate

\footnotetext{
${ }^{13}$ The reason for this is because the data were collected to assess wealth taxes. Stockholding under the mandatory first pillar of social security (part of which is invested in a fund) and in tax-deferred retirement accounts is not included because it is not part of the tax base.

${ }^{14}$ See Christelis, Georgarakos, Haliassos (2013), the references therein, and Yun (2004).
} 
effects"; the other, arising from different behavior by households belonging to different country groups but sharing similar characteristics, is attributed to "coefficient effects". Both terms refer to the components of a (probit) participation regression that makes the latent variable (the utility differential between participation and non-participation) a function of observable characteristics (“covariates") whose influence depends on the sign and magnitude of coefficients.

In all cases, we must specify a "base" cultural group, $s$, and then compare participation in each other group, indexed by $i$, for a given asset or debt. The decomposition of differences in observed participation rates into "coefficient" and "covariate" effects is represented by:

$$
p r^{s}-p r^{i}=\left\{p r^{s}-\hat{p}^{b^{s}, X^{i}}\right\}+\left\{\hat{p}^{b^{s}, X^{i}}-p r^{i}\right\}
$$

The key here is the computation of the counterfactual participation rate, $\hat{p}^{b^{s}, X^{i}}$. Households from the base group (e.g. Northerners excluding Swedes) would exhibit this average participation rate if they had the same characteristics as those of immigrants from country group $i$. The first difference term on the right-hand side represents the difference between the actual behavior of households from the base group and this counterfactual participation rate, so it represents "covariate effects". Both items in the second bracket refer to characteristics of immigrants from country group $i$, but the counterfactual probability term uses the coefficients for the base group. Because the difference is due to the use of different sets of coefficients, this second bracket represents "coefficient effects".

From an economic point of view, we want to purge from the overall observed difference in participation rates those differences attributable to differences in economic position and other observable characteristics and focus on differences across groups in the systematic relationship between household characteristics and participation behavior. In other words, whereas in the previous section we present the overall "raw" differences, in this section we discuss the second difference term on the right-hand side, i.e., coefficient effects.

To construct the counterfactual participation probability and derive the decomposition, we first run a participation probit regression for the relevant asset or debt among the base group and obtain the coefficients, $b^{s}$. We are able to control for a range of household characteristics (see the descriptive statistics in Table 3). Specifically, we include as regressors (log) disposable income, age categories, gender of head of household (following the Canberra definition of head of household), occupational dummies, marital status, household size (distinguishing between adults and children), educational attainment of head of household, dummy variables for whether 
the head of household works in the financial sector or for the government, and household netwealth quartile.

Once the probit coefficient estimates are obtained, we draw (randomly and with replacement) vectors of household characteristics from the immigrant population from country group $i$, thereby respecting any tendency of that group to co-vary. For each immigrant household drawn, we use the coefficient estimates for the households in the base group to compute the probability of participation that the immigrant household from group $i$ would exhibit if it behaved like a household in the base group. These counterfactual probabilities for all immigrant households drawn from group $i$ are then averaged to determine the counterfactual probability in question and thus to compute the estimate of the coefficient effect. Using bootstrap analysis (with 200 replications), we also report $p$-values for the statistical significance of the coefficient effects or systematic differences in the average participation behavior across the base group and immigrant households from country group $i$.

\subsubsection{Participation Regressions for the two Alternative Base Groups}

Computation of coefficient effects only requires probit estimation for the base group. We present here these regressions for two alternative base groups: Northerners excluding Swedes, who are used as the base group in the discussion of significance of differences in behavior across different culture groups; and Swedes, who are used as the base group when we discuss convergence in behavior with longer exposure to common institutions. ${ }^{15}$ Estimates are reported in the form of average marginal effects. In these tables, we pool all observation years for each base group and include year effects and regional fixed effects, clustering at the household level. ${ }^{16}$

The first two columns present results for stockownership. The results for Swedish households mirror standard findings in the participation literature. Higher position in net wealth distribution (after removing the value of stocks), higher educational attainment, work in the financial sector (but not in the government sector), and smaller number of adults all contribute positively to the probability of stock market participation outside retirement accounts. Interestingly, having a male head of household reduces the probability of participation. For the base group of Northerners (excluding Swedes), results share some common features, but there are also differences: being married is related to lower participation rates, and working in the

\footnotetext{
${ }^{15}$ A full set of participation probits for all of the cultural groups considered is presented in the Online Appendix, in Tables C.1, 2, and 3. Decomposition results using Swedes as base group for the first part of the analysis are also presented in OA.

${ }^{16}$ In our tables and figures of results, we track the evolution of coefficient effects through time. To do so, we run a separate participation probit for base households for each given year in the sample, including region fixed effects.
} 
financial sector is not significant. The relationship of participation to years in Sweden and to age at which immigration to Sweden took place is positive and negative, respectively

The debt participation regressions (in the next two columns) similarly yield the expected results from the existing literature on debt. Income is positively correlated to the probability of participation, as are household size and employee status. High school and college graduates are both more likely to participate in debt than are high school dropouts when one looks at Swedes, but this is not the same when one looks at Northern immigrants. Working in the financial sector or for the government is positively correlated with a Swedish household having outstanding debt, but again this is not the case for Northern immigrants.. Given household income, a higher level of gross wealth ${ }^{17}$ makes it less likely for household to be burdened with debt. For Northern immigrants, there is negative correlation between years in Sweden or age at immigration and having debt outstanding.

Homeownership is similarly linked to the control variables in standard ways (columns 5 and 6): higher incomes, older age, employment, household size, educational attainment, and working for the financial sector are all positively correlated with the probability of homeownership for Swedish households, whereas work in the financial sector is insignificant for Northern immigrants. The position in the net wealth distribution (after removing home value) correlates with homeownership, positively for Swedes and negatively for Northern immigrants. ${ }^{18}$

In the decompositions presented below, we wish to control for differences in characteristics among the compared groups, and we wish to trace the evolution of these differences through time. Thus, we run period-by-period probit regressions for the appropriate base sample, as described in the methodological section.

\subsubsection{Decomposition Results}

Figures 2a, b, and c (Tables D.1a, b, c) report our results from a decomposition of observed differences in participation rates between Northern households (excluding Swedes) and each of the other immigrant groups that we define based on cultural predispositions. We focus on coefficient effects, i.e., differences found when controlling for differences in household

\footnotetext{
17 In the three participation regressions, we follow the principle of removing the financial instrument being considered from the net wealth measure. This amounts to considering gross wealth when running the debt regression.

${ }^{18}$ When we run analogous probit regressions for each immigrant group separately, reported in the Online Appendix, we find broadly similar effects, although with variations in the size of marginal effects (and an occasional difference in the signs or statistical significance). Because average marginal effects exist across all households for each separate immigrant sample, these differences are partly due to different probit coefficients and partly due to differences in the configuration of characteristics of immigrant populations compared to the base population. Moreover, these results represent average behavior across the entire sample period.
} 
characteristics across groups. For stockholding, we find that Northern households tend to exhibit higher participation than the Balkans and RIP countries, even after controlling for characteristics, and that these coefficient effects are statistically significant throughout the period under examination. At the other extreme, all coefficient effects for Turks versus Northerners are statistically insignificant, signaling that all of the observed difference in stock market participation between these two immigrant groups could be attributed to differences in observed household characteristics. The same is true for the other two groups, but with exceptions of statistical significance in a few years.

With respect to debt participation (Figure 2b/Table D.1b), the Balkans are very close to the Northern and BALFIN groups, once characteristics are controlled for, with Turkey and RIP lagging considerably behind Northerners in this respect. This very different behavior of the Balkans with respect to stocks (in which they underparticipate) than with debt (in which they match the participation by Northerners of similar characteristics) suggests that their limited stockholding participation is unlikely to be due to a general lack of access to financial institutions and markets, but rather to a deliberate choice to abstain from stocks. ${ }^{19}$ Turkish immigrants' behavior is quite extraordinary: they begin by exhibiting a sizeable difference from Northern households, but they show a dramatically faster rate of convergence than anybody else during the 9-year period.

A factor that is very important for debt behavior is income growth expectations: could it be that the observed differences are largely explained by different income prospects perceived by the different immigrant groups in their host countries? Figure 3 and Table D.2 show that, although (perfect-foresight) two-year income-growth expectations are statistically significant and have the right (positive) sign in augmented participation probits for debt behavior, we find a very similar pattern of coefficient effects whether or not we incorporate this factor. Controlling for income expectations in this way has a noticeable effect only on the estimated differences between Northerners and Turkish immigrants: poorer income expectations of the latter explain part of their more limited tendency to participate in debt than that of Northerners with similar other characteristics.

Figure 2c (Table D.1c) exhibits results related to homeownership. Here, Turkish and Balkan immigrants lag far behind Northern households in their tendency to own a home, immigrants from BALFIN are very close to Northern households, and the other two groups lie in between.

\footnotetext{
19 Interestingly, the start of our sample period coincides with a peak in stock market participation in Greece, followed by a burst of the stock market bubble in 2000 and an exodus of Greek households from the stock market. These dramatic developments in the home country are not mirrored at all in Balkans operating under Swedish institutions.
} 
The figures and tables show that coefficient effects indicate convergence but tend to be quite persistent throughout the sample period, even though we find statistically significant effects of length of stay in the participation probits. We further explore this apparent conflict below.

\subsubsection{Are Differences Explained by Length of Stay in Host Country?}

The results on homeownership in particular raise the question of whether observed differences are trivially explained by the relative length of stay of different immigrant groups in Sweden rather than by deeply rooted cultural predispositions. The idea is that the decision to own a home, in the presence of down payment requirements and transactions costs, depends on having time to accumulate assets and a long enough horizon or perspective related to living in the country. Having spent a longer time in Sweden both contributes to the former and indicates the latter. Are statistically significant coefficient effects rendered insignificant simply by controlling for households' length of stay in each immigrant group?

The estimated coefficient effects of differences are plotted in Figure D.1a, b, c and reported in Table D.3a, b, c. Consistent with the findings noted in Figure 2, coefficient effects do not disappear once we control for length of stay in Sweden. In fact, their ranking and overall pattern for homeownership are the same as without this control. However, for stockholding we do find some changes, suggesting that length of stay is a potentially important factor that we should take seriously into consideration. Indeed, we do so in detail when we address the question of whether differences in participation behavior linked to cultural predispositions tend to diminish with the length of exposure to the local institutions.

\subsubsection{Are Differences Explained by Attitudes towards Immigrants?}

A further consideration is that the coefficient effects that we uncover do not primarily reflect differences in behavior across immigrants of different cultural backgrounds but simply are the effects of differential treatment of Northern versus other immigrant households by the Swedish financial sector. Indeed, this situation could even generate a rich pattern of coefficient effects simply because of differences in the geographical distribution of immigrant groups to areas that have either more positive or more negative attitudes towards immigrants.

To account for this possibility, we rerun the baseline probit for Northern households and explicitly introduce a proxy for regional attitudes towards immigrants. Specifically, we use survey data provided by FSI (org., Forskningsgruppen för Samhälls- och Informationsstudier) to construct such a measure. This survey is conducted every year on a representative sample of Swedish inhabitants from different municipalities over the period from 2000 to 2008 and 
includes different questions to capture respondents' attitudes about immigrants. ${ }^{20}$ To measure people's attitudes towards immigrants at the regional level, we use the share of people answering "To a lesser extent" to the survey question (translated from Swedish), "Do you think that Sweden should continue taking in immigrants/refugees to the same extent as it does now?" in the province where the household resides. ${ }^{21}$

The resulting estimates of coefficient effects and their significance are reported in Tables D. $4 \mathrm{a}, \mathrm{b}$, and $\mathrm{c}$ and in Figures D.2a, b, and c. It is evident from the results that discrimination against immigrants by the financial sector, even if present, is not an important factor in the coefficient effects that we are estimating. The same basic pattern of effects emerges, whether we focus on stockownership, debt participation or homeownership, reinforcing the view that these results are more likely to reflect differences in cultural backgrounds rather than differences in the treatment of immigrants from different cultural groups by the Swedish financial sector.

\section{The Interplay between Cultural Predispositions and Exposure to Institutions}

Having derived and discussed significant differences in financial behavior across groups defined in terms of genetic distance as an indicator of cultural differences, we now turn to the resilience of cultural differences to exposure to one set of institutions and policies (in this case, those of Sweden). The previous section has already established two results relevant to this issue. First, length of stay in Sweden is significant in all participation probit regressions for all financial instruments and for all country groups. Second, the pattern of differences does not seem to change substantially, with very few exceptions, over the period of observation (1999-2007). On their face, these two results appear to contradict each other and to call for further investigation. Are cultural predispositions completely impervious to exposure to one common set of institutions and policies, is the length of the sample period too short for us to observe major effects, or is there another important factor governing assimilation that still must be considered?

\subsection{Decomposition of Differences by Length of Exposure to Host Institutions}

To sharpen our understanding of the process of assimilation, we now look within immigrant groups sharing common cultural backgrounds and compare 'old-timers' to

\footnotetext{
${ }^{20}$ In a recent paper, Carlsson and Eriksson (2012) provide evidence that reported attitudes towards immigrants from the FSI survey correlate with actual discrimination in the Swedish housing market. Using a field experiment in the Swedish housing market, they find evidence for greater discrimination in the housing market in municipalities where a larger share of respondents of the FSI survey report negative attitudes towards immigrants.

21 The total number of answers to the FSI survey in 20 provinces was 19,424 , with a minimum of 285 persons surveyed per province. Out of 19,424 respondents, 55 percent reported a negative attitude towards immigrants, whereas 34 percent answered this question either with "To a larger extent" or "To the same extent", and the remaining 11 percent responded that they were "unsure or unwilling to answer".
} 
'newcomers'. In each case, we consider as 'old-timers' ('newcomers') those members of the immigrant group who have spent a longer (shorter) time in Sweden than the median time observed for members of that immigrant group. We now compare each of those two subgroups to Swedes (rather than to Northerners). The objective is to focus on the degree of assimilation to the local institutions and to the behavior of Swedish households. Figures $4 a, b$, and c and Tables D.5a, b, and c report the coefficient effects of differences relative to Swedish households, for each of the subsamples within each immigrant group.

In the two cases of asset participation (stocks and home), we find a clear pattern of substantially higher coefficient effect among newcomers than among old-timers. In some country groups, we even find clear signs of convergence of newcomers to old-timers within our sample period, although in other cases, the differences in coefficient effects appear to be more persistent. These findings suggest that patterns of asset market participation are amenable to exposure to a particular set of institutions, even when those patterns have not arisen naturally from the cultural background of a particular household (as is the case for immigrants exposed to institutions built by Swedes).

The pattern that we find for debt exhibits considerable diversity but has two major common patterns across most groups. First, in five out of six groups, newcomers begin the observation period less likely to borrow than comparable Swedish households, and they gradually bridge this difference as they stay longer. The only exception to this pattern is Balkans, who plunge into debt participation early on and gradually phase it out. Second, in four out of six cases (with the exceptions of BALFIN and immigrants from the northern countries, who tend to be culturally closest to the Swedes), within-group differences between old-timers and newcomers' behavior relative to that of Swedes tend to diminish rather than to increase over time. In the two exceptional groups, the reason for divergence is the unusual behavior of oldtimers, whereas newcomers exhibit a pattern of assimilation to Swedes' debt behavior consistent with that of most other groups. Clearly, the assimilation process seems much more complicated and diverse in the case of debt behavior than in the case of asset-ownership behavior.

\subsection{Accounting for Horizon}

It may be argued that the distance between those who have spent longer in the host country and newcomers is partly due to a difference in horizon: old-timers are more likely to have longer horizons for staying in Sweden in addition to having had a greater chance to be influenced by their environment. We pursue two sensitivity tests. First, we look only at (first-generation) immigrants who, regardless of their length of stay in Sweden, have decided to become Swedish 
citizens. Presumably, these immigrants share long horizons and a great willingness to assimilate. Does length of stay still make a difference for those people, controlling for culture group and for a wide range of observables? Figures D.3a, b, and c and Tables D.9a, b, c in the Online Appendix show that old-timers and newcomers are now somewhat closer together, primarily because newcomers who have already chosen to become Swedish citizens are closer to Swedes in terms of financial behavior. However, differences between old-timers and newcomers are still observed and are sizeable in most cases (Balkan, Turkey, RIP, and BALFIN). Moreover, these differences are found even when stacking the cards against finding length-of-stay effects, i.e., by focusing on people who demonstrate their great willingness to assimilate by becoming Swedish citizens. Overall, length of exposure to a common set of institutions does seem relevant for the harmonization of financial behavior, even when we study people with similar horizons and willingness to assimilate.

Second, in all of our analysis, we include only (Swedish and immigrant) households living in Sweden throughout the observation period. Thus, we may have excluded from the sample households that revealed a shorter horizon for living under Swedish institutions and therefore, a greater reluctance to adjust their behavior. A priori, one might expect inclusion of such emigrants to yield greater differences in behavior (coefficient effects) with Swedish households of similar observable characteristics, thus increasing our estimates of cultural differences in financial behavior. The question is non-trivial, however, given that emigrants are also added to the Swedish subsample, and their inclusion could mitigate differences with the immigrant subsamples because all emigrants exhibit shorter horizons for life in Sweden. Even less clear is what inclusion of emigrants would imply for the rate and extent to which newcomers in any given culture group converge in behavior to the corresponding old-timers and to Swedes.

Tables D.10a, b, and c present estimated coefficient effects for a sample that includes immigrants and Swedes who left Sweden during the observation period. ${ }^{22}$ We find that estimated coefficient effects vis-à-vis Swedish households are larger when emigrants are included in the sample, and this holds both for old-timers and for newcomers. Second, the increase in estimated coefficient effects is bigger for the newcomers than for the old-timers in each culture group. This implies an even greater adjustment in newcomers' financial behavior to that of old-timers than in our original sample. Unlike in the base sample, this greater adjustment is accomplished through two channels: adjustment of behavior and emigration of those who do not see themselves as working under Swedish institutions for long. Nevertheless, the estimated coefficient effects of

\footnotetext{
${ }^{22}$ Over time, the structure of this sample converges to that used in our baseline analysis as emigrant households depart.
} 
old-timers are only marginally higher than those in the original sample, consistent with the notion that convergence to Swedish financial behavior does occur.

Tables D.10a, b, and c, together with Table D.11, where the share of leavers is reported, confirm that the increase in estimated coefficient effects resulting from including emigrants tends to be greater for those culture groups that have a larger share of emigrants. ${ }^{23}$ This serves to illustrate a further point: culturally motivated differences in financial behavior in the face of harmonized institutions are smaller, the greater the fraction of people in the population that have longer horizon. In turn, longer horizons are associated with the perceived permanence of institutions and acceptance of them, which translates into willingness to stay in the country.

\subsection{Decomposition of Differences by Prior Exposure to Home Institutions}

A different angle on understanding the assimilation process with respect to financial behavior is obtained by examining the importance of the age at which a first-generation immigrant moved to Sweden. We resume consideration of the balanced sample (without emigrants) and distinguish between immigrants who moved prior to the age of 18 (whom we label "early") and those who moved when they were already adults (labeled "late"). We have two main motivations for studying this data split. The first is that those who moved as adults had been exposed to home institutions in their economic life and they may well have been influenced by the way things were done at home. We would expect these people to take longer to assimilate to host country practices. The second reason is that those who moved younger than 18 are likely a group less subject to selection than those who decided to migrate to Sweden. Because they were minors, they did not themselves choose to move to Sweden. Potential selection bias works in our favor when studying the presence of culture-based differences in behavior and against us when studying the degree of resilience of cultural predispositions to exposure to host country institutions. If it is indeed the case that those who move do so primarily because they like Swedish institutions and culture, we should be less likely to find significant, culture-based differences in behavior. On the other hand, if immigrants indeed are heavily selected in this way, we would expect to find a greater degree and speed of assimilation to the host country culture. If we manage to find statistically significant coefficient effects even for those who (were) moved to Sweden before they were adults, we strengthen the case for the importance of cultural factors to household financial behavior. ${ }^{24}$

\footnotetext{
${ }^{23}$ The shares are small, ranging from approximately $2.15 \%$ in Turkey to $7.25 \%$ in SUFI.

${ }^{24}$ Note that the use of first-generation immigrants is useful for the institutional harmonization experiment that we have in mind because our primary goal is to approximate short- to medium-run adjustment to the program. This depends on the response of people who were exposed to pre-existing institutions.
} 
Figures 5a, b, and c show coefficient effects when each immigrant group is split according to whether the head of household moved to Sweden as an adult ("late") or not ("early"), whereas Tables D.6a, b, and c show the estimated magnitudes and $p$-values for the various coefficient effects. A glance at the tables shows that certainly for the case of the two assets (stocks and homes), coefficient effects remain statistically significant even for those who moved prior to adulthood. For debt participation, the picture is more mixed, but there is still ample evidence of statistically significant coefficient effects even for those who moved young.

The figures show that with only two exceptions, those who moved prior to age 18 exhibit smaller or similar estimated coefficient effects to members of the same country group who moved during adulthood. One exception refers to northerners and homeownership and the other to Balkans and debt. Regarding northerners, it can be argued that Northern culture and institutions are the closest to Swedish ones and thus, exposure to the home country is equivalent to exposure to the host country. For the Balkans, we have already noted unusual behavior with regard to debt participation. Our findings here suggest that the unusually high participation rates relative to comparable Swedes in the early part of the sample period is primarily associated with Balkans who emigrated after age 18, and which stands in stark contrast to the debt behavior of those not exposed to home country institutions during their adult economic lives. Nevertheless, even in the case of late immigrants, Balkans appear to reverse this tendency quickly, so that by 2003 they already had begun to exhibit more limited debt participation than Swedish households with similar characteristics.

\subsection{Exposure to Formal versus Informal Institutions}

Although examination of immigrant behavior in the face of host country institutions and policies foreign to their own cultures can tell us a great deal about likely behavior under exogenously harmonized institutions and transplanted best practices, it can be argued that immigrants are exposed to more than the formal institutions. By living in Sweden, they come in contact with Swedes and learn informal aspects of Swedish culture that help them understand better how to operate under Swedish formal institutions. In a harmonization experiment, transplanted institutions might be new to all people in a country. Our analysis of immigrants could thus bias downward the estimates of the size of differences due to cultural predisposition and bias upwards the rate of assimilation to foreign institutions.

To get a sense of the likely bias, we identify and remove from the sample households whose head is married to a Swedish citizen born in Sweden. The idea is that such heads of household learn a great deal both from their partner and from their partner's relatives and long- 
time friends. If our results are due to the presence of such intensive interaction for some households, we would expect estimated cultural differences to be considerably larger for the remaining sample and the rate of convergence to Swedish financial behavior considerably slower.

Results for this restricted sample are shown in Figures 6a, b, and c (Tables D.7a, b, c). ${ }^{25}$ Comparing those with the figures on the full sample (Figs. 5a, b, c), we find that the pattern of cultural differences, the rate at which newcomers converge to the financial behavior of oldtimers in their group, and the difference between old-timers and natives are robust to the exclusion of such intensely interacting households in the full sample. Of course, households remaining in the sample also interact with Swedes, albeit to a more limited extent than those excluded, and sharpening our understanding of the effects of social interactions on the convergence of financial behavior is an ongoing project of ours. Nevertheless, findings for the restricted sample here are quite relevant to the institutional harmonization experiment because peripheral countries themselves include people familiar with the 'northern' institutions, e.g., because they have lived or studied there.

\subsection{Decomposition of Differences by Presence of a Swedish Citizen}

Finally, we split each immigrant sample depending on whether the head of household has Swedish citizenship. Deciding to apply for Swedish citizenship is a strong signal of assimilation to host country culture and a signal of a long horizon in the country. The results are shown in Figures D.5a, b, and c and in Tables D.8a, b, and c. Two observations stand out. First, immigrant households with a Swedish citizen head tend to exhibit smaller estimated differences in financial behavior compared to native Swedish households of comparable characteristics than members of the same immigrant group whose head is not a Swedish citizen. Second, and perhaps more strikingly, even immigrants whose heads of household have obtained Swedish citizenship tend to exhibit statistically significant coefficient effects compared to indigenous Swedish households.

\section{Interpretation, Robustness and Limitations}

In interpreting the findings, one needs to be careful about certain issues. We describe those and our approach to addressing them in this section. One issue is the interaction between culture and institutions, brought out very vividly in the Alesina and Giuliano (2014) paper. While it is plausible in general that culture influences institutions and vice versa, our approach has the

\footnotetext{
${ }^{25}$ Interestingly, the percentages of immigrants married to a Swedish citizen born in Sweden differ across cultural groups in a way consistent with cultural distance. They are lowest for Turks and Balkans (3 to 5\%), highest for northerners (31\%), and in between for the other three groups (17 to $20 \%$ ).
} 
advantage that each immigrant group is small and unlikely to exert a noticeable influence on the institutions of the host country. Thus, the direction of influence is likely to run from institutions developed by Swedes to the culture of immigrants in the process of assimilation. The fact that, in our setup, institutions were developed by Swedes rather than the immigrants themselves also serves another purpose, namely to fit the topical policy question of whether exogenously harmonized institutions in the European Union are likely to influence (financial) behavior of households whose cultural predispositions may be foreign to those institutions.

Analysis of immigrant populations raises two further issues. The first is that immigrants typically choose the host country rather than being assigned to it, so they may be choosing countries to whose institutions they feel close. Endogenous choice of host country may be an issue for estimating the degree of assimilation, but it actually works against finding statistically significant differences between immigrants and natives. In our econometric analysis, we have found statistically significant differences in behavior, both between immigrants and Swedes (not reported in the main body of the paper) and across different immigrant groups.

Is endogenous choice of host the reason we find assimilation? First, we have established variation in cultural distance to Sweden across immigrant groups, and we find convergence in behavior to Swedish institutions even for those with the greatest cultural distance to Swedish institutions. Second, we have examined robustness of our findings to having moved as a child rather than as an adult: those who were moved to Sweden by their parents actually exhibit smaller (but still significant) differences in behavior than those who chose to move as adults, controlling for many characteristics. Third, we removed from our estimation sample those who chose to marry a Swede, or those who took on Swedish citizenship, as more likely to feel similar to the locals or to have access to informal channels of transmission of values and beliefs. In both cases, we still find assimilation. Fourth, even if assimilation is partly due to endogenous choice of host country, this is still consistent with the policy implication we have drawn, namely that voluntary acceptance of (harmonized) institutions leads to convergence of financial behavior. Our findings suggest that Europeans are likely to adapt their behavior if they accept the necessity of institutional harmonization, but they are silent as to convergence in behavior by populations who do not accept the institutional harmonization program.

The second issue raised by the use of immigrant samples is that arguably "immigrants are immigrants" and they may differ from natives in ways we cannot control for, even using our broad array of observable characteristics. If valid, failure to account for this would overstate the observed differences in behavior between immigrants and Swedes of comparable observable 
characteristics. However, a fundamental unobserved difference between immigrants and natives could actually work against finding assimilation and convergence to the financial behavior of native Swedes. In order to minimize the risk of overstating differences in behavior attributable to culture, we have chosen to report in the paper the estimates of differences in behavior based on comparison of immigrants to immigrants (the Northern immigrant group versus other immigrant groups), rather than between immigrants and natives. ${ }^{26}$

Finally, should we expect our findings regarding differences in financial behavior across culture groups to mimic a comparison between current inhabitants of the original countries? Even if adequate and comparable data on participation patterns of residents of those countries and culture groups were available (which is not the case generally), there is no compelling reason for financial behavior to be similar across home country residents and immigrants from that country to Sweden. Immigrants are at least twice removed from their compatriots residing in the home country: they decide their financial behavior on the basis of Swedish rather than home institutions; and they are immigrants to a foreign country rather than residents in their own.

\section{Conclusions}

In this paper, we first classify European countries into different culture groups in a robust way, using two independent classification criteria: genetic distance and responses to the Hofstede culture-relevant questions. Contrary to perceptions of some, we find that there is no unique 'southern culture' but rather a single northern culture, a set of values and beliefs that distinguishes northern Europeans from quite heterogeneous other European cultures.

We then employ this classification to examine whether asset and debt participation decisions of households differ across those groups, controlling for heterogeneity in group characteristics; and whether they tend to converge with longer exposure to a common set of institutions. We use high-quality administrative data on immigrants to Sweden for purposes of our analysis.

We adopt an econometric approach that focuses on differences in the link between household characteristics and financial behavior. This overcomes a number of restrictive assumptions in the extant literature on different aspects of immigrant behavior, and is flexible enough to allow these links to differ across culture groups, over time, and across subsets of the same group of immigrants. We find that statistically significant differences in financial behavior across culture groups do exist, but they tend to diminish with the time of exposure to common institutions, even in the case of countries with greatest cultural distance from the one that created the institutions.

\footnotetext{
${ }^{26}$ In a previous version of the paper, we have reported results comparing immigrants to Swedes. We find a rich pattern of statistically significant differences there, as well (see Online Appendix).
} 


\section{References}

Alesina, Alberto, Arnaud Devleeschauwer, William Easterly, Sergio Kurlat, and Roman Wacziarg, 2003, "Fractionalization”, Journal of Economic Growth 8, pp. 55-194.

Alesina, Alberto, and Paola Giuliano, 2010, "The Power of the Family", Journal of Economic Growth 15, pp. 93-125.

Alesina, Alberto, and Paola Giuliano, 2011, "Preferences for Redistribution", in. J. Benhabib, M. Jackson and A. Bisin (ed.), Handbook of Social Economics, Amsterdam, the Netherlands: Elsevier.

Alesina, A. and P. Giuliano, 2013, "Family Ties", in Handbook of Economic Growth, P. Aghion and S. Durlauf (eds.), North Holland, Elsevier.

Alesina, Alberto, and Paola Giuliano, 2014, "Culture and Institutions", Working Paper, September.

Betermier, Sebastian, Thomas Jansson, Christine Parlour, and Johan Walden, 2012, "Hedging Labor Income Risk", Journal of Financial Economics 105, pp. 622-639.

Bogaard, Hein, and Christo Pirinsky, 2011, "Cultural Heritage and Financial Development", Working Paper.

Borjas, George J., 2002, "Homeownership in the Immigrant Population", Journal of Urban Economics, 52, pp. 448-476.

Carroll, Christopher D., Byung-Kun Rhee, and Chanyong Rhee, 1994, "Are There Cultural Effects On Saving? Some Cross-Sectional Evidence", Quarterly Journal of Economics 109, pp. 685-699.

Cavalli-Sforza, Luigi L, Paolo Menozzi, and Alberto Piazza, 1994, "The History and Geography of Human Genes", Princeton, NJ: Princeton University Press.

Christelis, Dimitris, Dimitris Georgarakos, and Michael Haliassos, 2013, "Differences in Portfolios across Countries: Economic Environment versus Household Characteristics", Review of Economics and Statistics 95, pp. 220-236.

Chui, Andy C.W., Sheridan Titman, and K.C. John Wei, 2010, "Individualism and Momentum around the World", Journal of Finance, pp. 361-392.

Desmet, Klaus, Michel Le Breton, Ignacio Ortuno Ortin, and Shlomo Weber, 2011, "The Stability and Breakup of Nations: A Quantitative Analysis", Journal of Economic Growth 16, pp. 183-213.

Fernandez, Raquel, and Alessandra Fogli, 2006, "Fertility: The Role of Culture and Family Experience”, Journal of the European Economic Association 4, pp. 552-561.

Fernandez, Raquel, and Alessandra Fogli, 2009, "Culture: An Empirical Investigation of Beliefs, Work and Fertility”, American Economic Journal: Macroeconomics 1, pp. 146-177.

Fisman, Raymond and Edward Miguel, 2007, "Corruption, Norms, and Legal Enforcement: Evidence from Diplomatic Parking Tickets”, Journal of Political Economy 115, pp. 10201048 .

Georgarakos, Dimitris, Michael Haliassos, and Giacomo Pasini, 2014, "Household Debt and Social Interactions", forthcoming in the Review of Financial Studies.

Giuliano, Paola, Antonio Spilimbergo, and Giovanni Tonon, 2013, "Genetic Distance, Transportation Costs, and Trade”, Journal of Economic Geography, pp. 1-20. 
Guiso, Luigi, Paolo Sapienza, and Luigi Zingales, 2003, "People's Opium? Religion and Economic Attitudes", Journal of Monetary Economics, 50(1), pp. 225-282.

Guiso, Luigi, Paolo Sapienza, and Luigi Zingales, 2004, "The Role of Social Capital in Financial Development”, American Economic Review 94, pp. 526-556.

Guiso, Luigi, Paolo Sapienza, and Luigi Zingales, 2006, "Does Culture Affect Economic Outcomes?", Journal of Economic Perspectives 20, pp. 23-48.

Guiso, Luigi, Paolo Sapienza, and Luigi Zingales, 2008, “Trusting the Stock Market”, Journal of Finance 63, pp. 2557-2600.

Guiso, Luigi, Paolo Sapienza, and Luigi Zingales, 2009, "Cultural Biases in Economic Exchange?", Quarterly Journal of Economics 124, pp. 1095-1131.

HFCS Report on the Results from the First Wave (2013). Available from: www.ecb.europa.eu/home/html/researcher_hfen.en.html

Haliassos, Michael, Thomas Jansson, and Yigitcan Karabulut, 2015, Online Appendix to "Incompatible European Partners? Cultural Predispositions and Household Financial Behavior", www.wiwi.uni-frankfurt.de/professoren/haliassos/research.html.

Hofsede, Geert, 1980, “Culture's Consequences: International Differences in Work-Related Values", Beverly Hills, CA: Sage Publications.

Hofsede, Geert, 2001, “Culture's Consequences: Comparing Values, Behaviors, Institutions, and Organizations across Nations", $2^{\text {nd }}$ Edition, Beverly Hills, CA: Sage Publications.

Kountouris, Yiannis, and Kyriaki Remoundou, 2013, "Is There a Cultural Component in Tax Morale? Evidence from Immigrants in Europe", Journal of Economic Behavior and Organization 96, pp. 104-119.

Luttmer, Erzo F. P., and Monica Singhal, 2011, "Culture, Context, and the Taste for Redistribution”, American Economic Journal: Economic Policy 3, pp. 157-179.

Osili, Una Okonkwo, and Anna L. Paulson, 2008a, "Institutions and Financial Development: Evidence from International Migrants in the United States", Review of Economics and Statistics 90, pp. 498-517.

Osili, Una Okonkwo, and Anna L. Paulson, 2008b, "What Can We Learn about Financial Access from U.S. Immigrants? The Role of Country of Origin Institutions and Immigrant Beliefs", World Bank Economic Review 22, pp. 431-455.

Oyelere, Ruth Uwaifo, and Willie Belton, 2012, “Coming to America: Does Having a Developed Home Country Matter for Self-Employment in the United States?", American Economic Review: Papers \& Proceedings 102, pp. 538-542.

Siegel, Jordan I, Amir N. Licht, and Shalom H. Schwartz, 2011, „Egalitarianism and International Investment", Journal of Financial Economics 102, pp. 621-642.

Spolaore, Enrico, and Romain Wacziarg, 2009, “The Diffusion of Development”, Quarterly Journal of Economics 124, pp. 469-529.

Tabellini, Guido, 2010, "Culture and Institutions: Economic Development in the Regions of Europe", Journal of the European Economic Association 8, pp. 677-716.

Yun, Myeong-Su, 2004, "Decomposing Differences in the First Moment", Economics Letters 82 , pp. $275-280$. 
Table 1: European Countries Grouped by the $F_{S T}$ Dominant Genetic Distance Measure

\begin{tabular}{|c|c|c|c|c|c|}
\hline Balkan & BALFIN & SUFI & Northern & $R I P$ & Turkey \\
\hline Bulgaria & Estonia & Belgium & Austria & Belarus & Turkey \\
\hline Croatia & Finland & France & Czech Republic & Italy & \\
\hline Slovenia & Hungary & Iceland & Denmark & Malta & \\
\hline Bosnia \& Herzegovina & Latvia & Rep. of Ireland & Germany & Portugal & \\
\hline Cyprus & Lithuania & Luxembourg & Netherlands & Russian Federation & \\
\hline FYROM & & Northern Ireland & Norway & Ukraine & \\
\hline Greece & & Poland & Slovakia & (Former) Soviet Union & \\
\hline Moldova & & Spain & Sweden & & \\
\hline Montenegro & & United Kingdom & Switzerland & & \\
\hline Romania & & & (Former) Czechoslovakia & & \\
\hline Serbia & & & (Former) German DR & & \\
\hline $\begin{array}{c}\text { (Former) Serbia \& Montenegro } \\
\text { (Former) Yugoslavia }\end{array}$ & & & & & \\
\hline
\end{tabular}

Note: This table presents the European countries grouped by the $F_{S T}$ measure of genetic distance across countries based on the dominant population group within each country in the sense of plurality. The data on the $F_{S T}$ measure come from Cavalli-Sforza, Monozzi, Piazza (1994) and Spolaore and Wacziarg (2009). Our sample includes all European countries except Albania, Andorra, Lichtenstein, San Marino, Monaco, and Vatican City. The exclusion of these countries from the sample is dictated by the data availability on the $F_{S T}$ measure. $F_{S T}$ genetic distance is the bilateral distance between county pairs and is directly computed from the allele frequencies of the major ethnic groups of each country in a pair. The groupings are constructed using the single-link hierarchical method as described in Jain and Dubes (1988). 
Table 2: Sample Participation Rates by Country Groups

Percentage of relevant (Household, Year) pairs recording participation events

\begin{tabular}{|c|c|c|c|c|c|c|c|c|}
\hline & Full Sample & Sweden & Balkan & $B A L F I N$ & SUFI & $\begin{array}{l}\text { Northern } \\
\text { (excl. } \\
\text { Sweden) }\end{array}$ & $R I P$ & Turkey \\
\hline \multicolumn{9}{|l|}{ Dependent variables } \\
\hline Stockownership & $64 \%$ & $73 \%$ & $32 \%$ & $51 \%$ & $52 \%$ & $55 \%$ & $49 \%$ & $45 \%$ \\
\hline Having debt outstanding & $77 \%$ & $80 \%$ & $79 \%$ & $69 \%$ & $70 \%$ & $68 \%$ & $61 \%$ & $65 \%$ \\
\hline Homeownership & $66 \%$ & $73 \%$ & $37 \%$ & $59 \%$ & $53 \%$ & $63 \%$ & $49 \%$ & $32 \%$ \\
\hline Number of Households & 215,957 & 143,217 & 18,652 & 27,916 & 6,861 & 13,327 & 2,020 & 3,964 \\
\hline Number of Observations & $1,943,613$ & $1,288,953$ & 167,868 & 251,244 & 61,749 & 119,943 & 18,180 & 35,676 \\
\hline
\end{tabular}

Note: This table presents the sample participation rates for stockownership, having debt outstanding, and homeownership rates of households in the LINDA database. The Northern group excludes Swedish households. The sample is a balanced panel of 215,957 households for the years 1999-2007 (i.e., 9 years). The participation rates for each group are calculated on the full pooled sample. Stocks include all forms of direct and indirectly held stocks, except stocks held through retirement accounts; debt includes all forms of debt (e.g., consumer credits, mortgages), except student loans; and homeownership includes both single-dwelling houses and tenant-owner dwellings (in the form of residential cooperatives). The country groupings are based on genetic distance (see notes to Table 1). Source: Author computations using LINDA data from Statistics Sweden. 
Table 3: Household Control Variables by Country Groups

\begin{tabular}{|c|c|c|c|c|c|c|c|c|}
\hline & Full Sample & Sweden & Balkan & BALFIN & SUFI & $\begin{array}{l}\text { Northern } \\
\text { (excl. } \\
\text { Sweden) }\end{array}$ & $R I P$ & Turkey \\
\hline Disposable income (in SEK) & 319,219 & 343,287 & 279,175 & 259,555 & 288,915 & 276,839 & 268,866 & 278,883 \\
\hline Log disposable income & 12.49 & 12.56 & 12.40 & 12.29 & 12.36 & 12.33 & 12.29 & 12.38 \\
\hline Age $<30$ & $4 \%$ & $4 \%$ & $4 \%$ & $1 \%$ & $4 \%$ & $2 \%$ & $3 \%$ & $8 \%$ \\
\hline $30 \leq$ Age $<45$ & $32 \%$ & $34 \%$ & $40 \%$ & $17 \%$ & $28 \%$ & $18 \%$ & $28 \%$ & $49 \%$ \\
\hline $45 \leq$ Age $<60$ & $37 \%$ & $36 \%$ & $38 \%$ & $43 \%$ & $46 \%$ & $32 \%$ & $34 \%$ & $31 \%$ \\
\hline $60 \leq$ Age & $28 \%$ & $25 \%$ & $18 \%$ & $39 \%$ & $21 \%$ & $48 \%$ & $35 \%$ & $11 \%$ \\
\hline Male & $65 \%$ & $69 \%$ & $66 \%$ & $55 \%$ & $52 \%$ & $61 \%$ & $58 \%$ & $61 \%$ \\
\hline Unemployed & $11 \%$ & $9 \%$ & $23 \%$ & $11 \%$ & $16 \%$ & $10 \%$ & $18 \%$ & $26 \%$ \\
\hline Retired & $24 \%$ & $20 \%$ & $20 \%$ & $36 \%$ & $20 \%$ & $40 \%$ & $29 \%$ & $18 \%$ \\
\hline Employed & $64 \%$ & $69 \%$ & $55 \%$ & $52 \%$ & $62 \%$ & $49 \%$ & $51 \%$ & $54 \%$ \\
\hline Student & $1 \%$ & $1 \%$ & $2 \%$ & $1 \%$ & $2 \%$ & $1 \%$ & $3 \%$ & $2 \%$ \\
\hline Married & $56 \%$ & $56 \%$ & $72 \%$ & $45 \%$ & $50 \%$ & $50 \%$ & $52 \%$ & $83 \%$ \\
\hline Number of adults & 1.85 & 1.87 & 2.05 & 1.66 & 1.76 & 1.68 & 1.75 & 2.40 \\
\hline Number of children & 0.75 & 0.84 & 0.91 & 0.35 & 0.60 & 0.39 & 0.49 & 1.51 \\
\hline High school graduate & $46 \%$ & $46 \%$ & $50 \%$ & $44 \%$ & $43 \%$ & $48 \%$ & $32 \%$ & $33 \%$ \\
\hline College graduate & $29 \%$ & $31 \%$ & $23 \%$ & $20 \%$ & $41 \%$ & $27 \%$ & $41 \%$ & $10 \%$ \\
\hline Household net wealth (in SEK) & 982,965 & $1,184,234$ & 210,580 & 665,298 & 700,838 & 939,069 & 654,908 & 385,739 \\
\hline Working in the financial sector & $1 \%$ & $2 \%$ & $0 \%$ & $1 \%$ & $1 \%$ & $1 \%$ & $1 \%$ & $0 \%$ \\
\hline Working for the government & $20 \%$ & $23 \%$ & $13 \%$ & $17 \%$ & $21 \%$ & $16 \%$ & $18 \%$ & $14 \%$ \\
\hline Time in Sweden & - & - & 17.4 & 34.6 & 22.5 & 33.8 & 24.4 & 21.1 \\
\hline Age at immigration & - & - & 30.2 & 20.8 & 27.3 & 22.9 & 28.0 & 22.9 \\
\hline Year of immigration & - & - & 1985.6 & 1968.4 & 1980.5 & 1969.2 & 1978.6 & 1981.9 \\
\hline
\end{tabular}

Note: This table presents the mean values for characteristics of households in the LINDA database. The Northern group excludes Swedish households. The sample is a balanced panel of 215,957 households for the years 1999-2007 (i.e., 9 years). The mean values are calculated on the full pooled sample. All monetary values are defined in SEK. For variable definitions, please see the Data Appendix. The country groupings are based on genetic distance (see Notes to Table 1). Source: Author computations using LINDA data from Statistics Sweden. 
Table 4: Participation Regressions for the Base Country Groups in the Decomposition Analyses

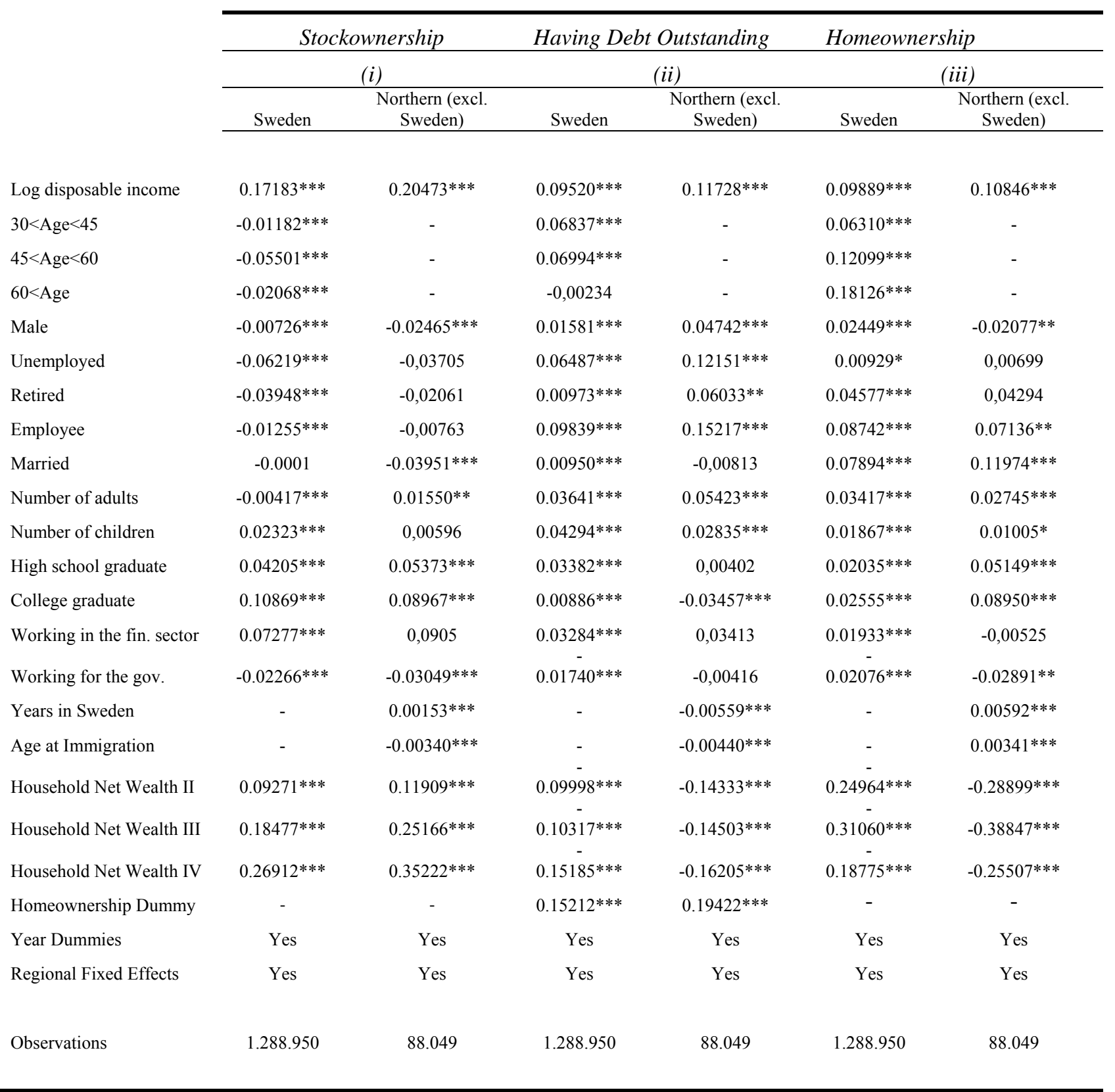

Note: This table presents the marginal effects for probit models that are estimated for the Swedish and the Northerner country grouping (excl. Swedish households) separately. The Northern group excludes Swedish households. The sample period includes 9 years from 1999 to 2007 . In Column I, the dependent variable is an indicator variable for stockownership. Stocks include all forms of direct and indirectly held stocks, except stocks held through retirement accounts. In Column II, The dependent variable is an indicator variable for having debt outstanding. Debt includes all forms of debt (e.g., consumer credits, mortgages), except student loans. Finally, in Column III, the dependent variable is an indicator variable for homeownership. Homeownership includes both single-dwelling houses and tenant-owner dwellings. We use the Northerners as the base group in the counterfactual analyses in Section 5, whereas we use the Swedish households as the base group in the analyses in Section 6. The standard errors are corrected for any heteroskedasticity by clustering at household level. We control for both time fixed effects and regional fixed effect by including year dummies and regional dummies. The country groupings are based on genetic distance (see Notes to Table 1). 
Figure 1: European Country Clusters Based on the $F_{S T}$ Dominant Genetic Distance Measure - Dendrogram

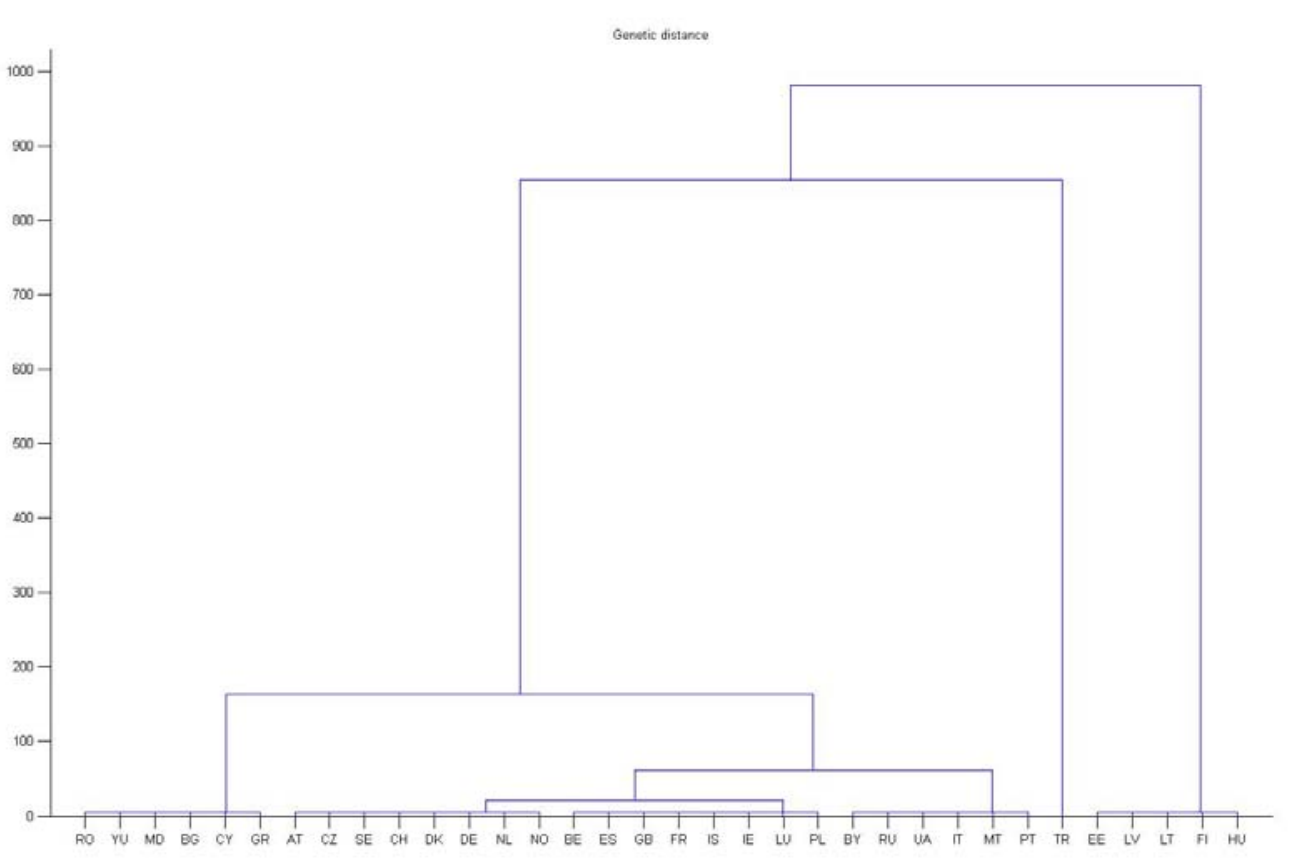

Note: This figure presents the European countries grouped by the $F_{S T}$ measure of Cavalli-Sforza, Monozzi, Piazza (1994). Our sample includes all European countries except Albania, Andorra, Lichtenstein, San Marino, Monaco, and Vatican City. The exclusion of these countries from the sample is dictated by the data availability on the $F_{S T}$ measure. $F_{S T}$ genetic distance is the bilateral distance between county pairs and is directly computed from the allele frequencies of the major ethnic groups of each country in a pair. The clusters are constructed using the single-link hierarchical clustering method described in Jain and Dubes (1988). The data on the $F_{S T}$ measure come from Cavalli-Sforza, Monozzi, Piazza (1994) and Spolaore and Wacziarg (2009). 
Figure 2a: Stockownership: Differences in Participation Rates due to Coefficients

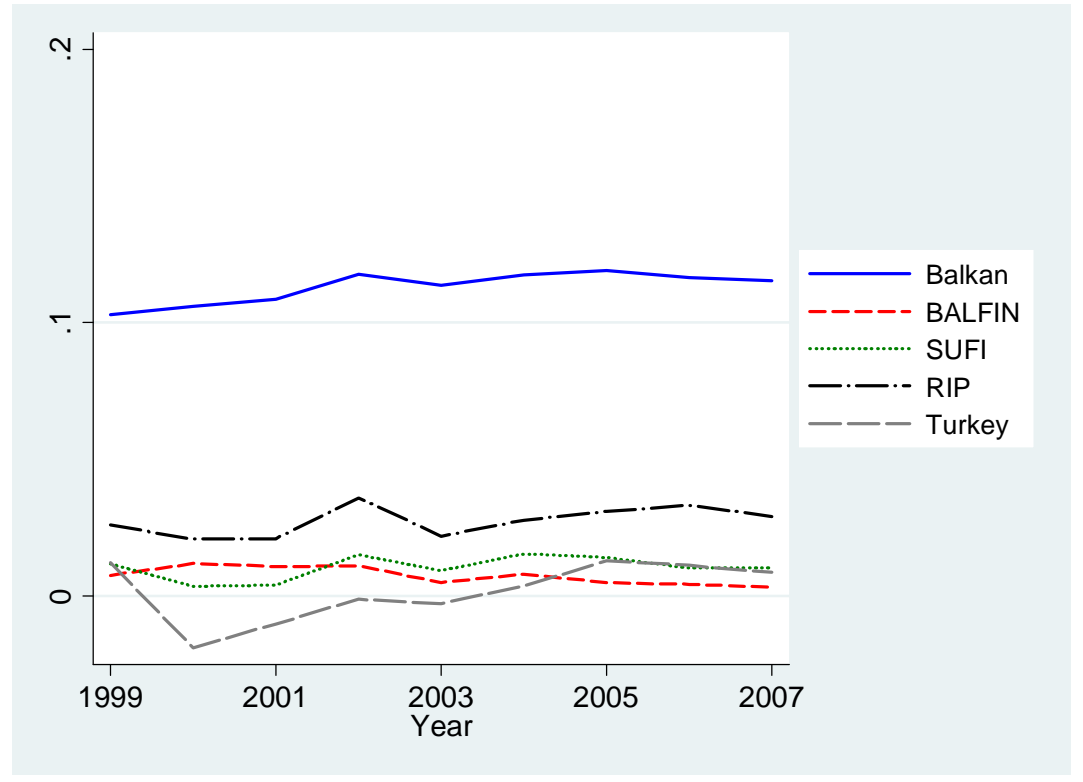

Note: This figure depicts the mean differences in stockownership rates due to coefficients between the Northerners (excl. Swedes) and other European households. Stocks include all forms of direct and indirectly held stocks, except stocks held through retirement accounts. The sample period includes 9 years from 1999 to 2007. All decompositions refer to shortfalls relative to Northern households. Standard errors are computed using 200 bootstrap replications. The country groupings are based on genetic distance (see Notes to Table 1). Source: Author computations using LINDA data from Statistics Sweden.

Figure 2b: Having Debt Outstanding: Differences in Participation Rates due to Coefficients

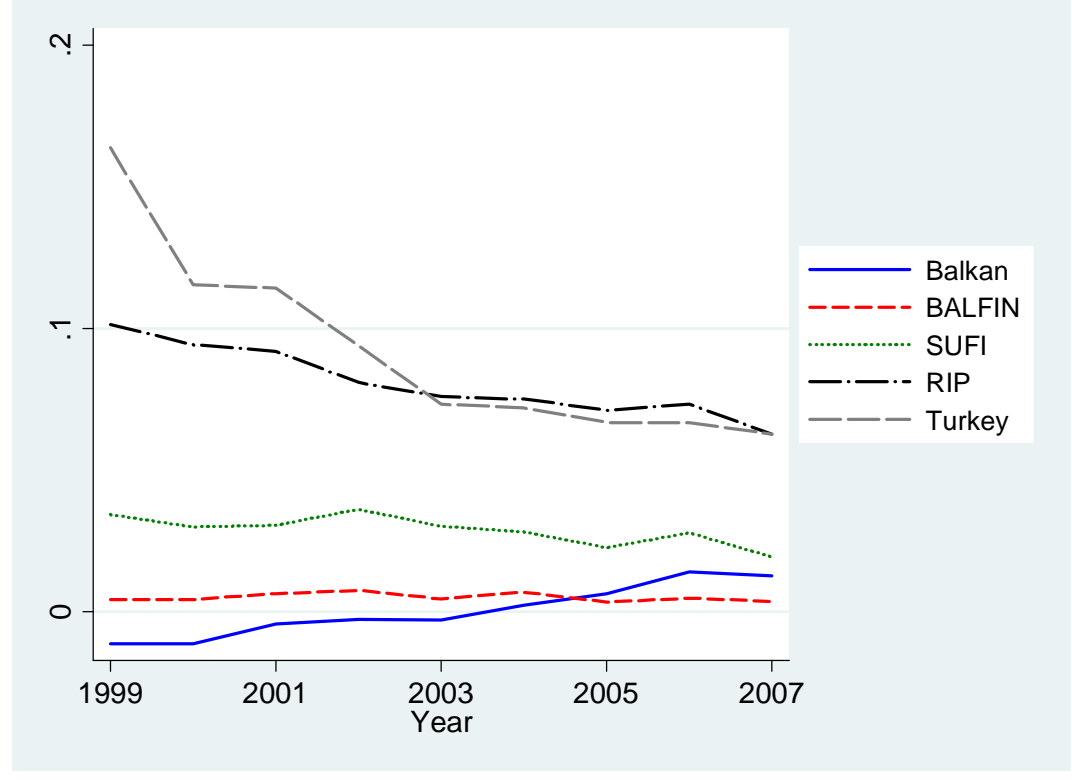

Note: This figure depicts the mean differences in having debt outstanding due to coefficients between the Northerners (excl. Swedes) and other European households. Debt includes all forms of debt (e.g., consumer credits, mortgages), except student loans. The sample period includes 9 years from 1999 to 2007. All decompositions refer to shortfalls relative to Northern households. Standard errors are computed using 200 bootstrap replications. The country groupings are based on genetic distance (see Notes to Table 1). Source: Author computations using LINDA data from Statistics Sweden. 
Figure 2c: Homeownership: Differences in Participation Rates due to Coefficients

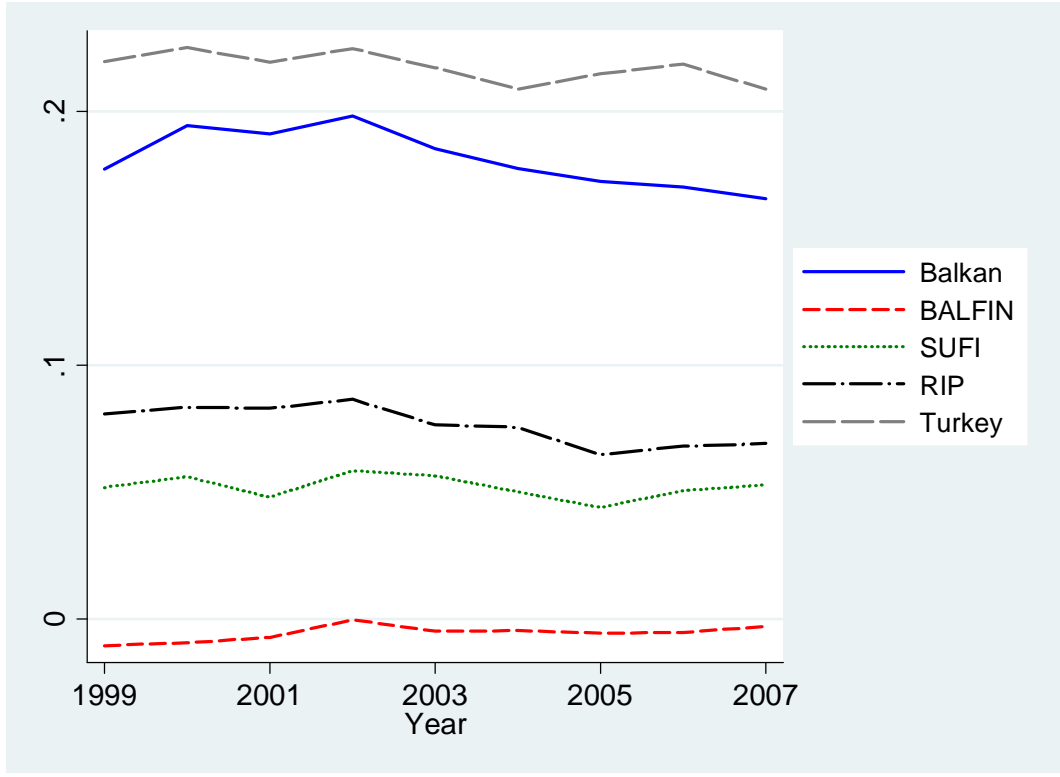

Note: This figure depicts the mean differences in homeownership rates due to coefficients between the Northerners (excl. Swedes) and other European households. Homeownership includes both single-dwelling houses and tenant-owner dwellings. The sample period includes 9 years from 1999 to 2007. All decompositions refer to shortfalls relatives to Swedish households. Standard errors are computed using 200 bootstrap replications. The country groupings are based on genetic distance (see Notes to Table 1). Source: Author computations using LINDA data from Statistics Sweden.

Figure 3: Having Debt Outstanding: Controlling for Income Growth Expectations

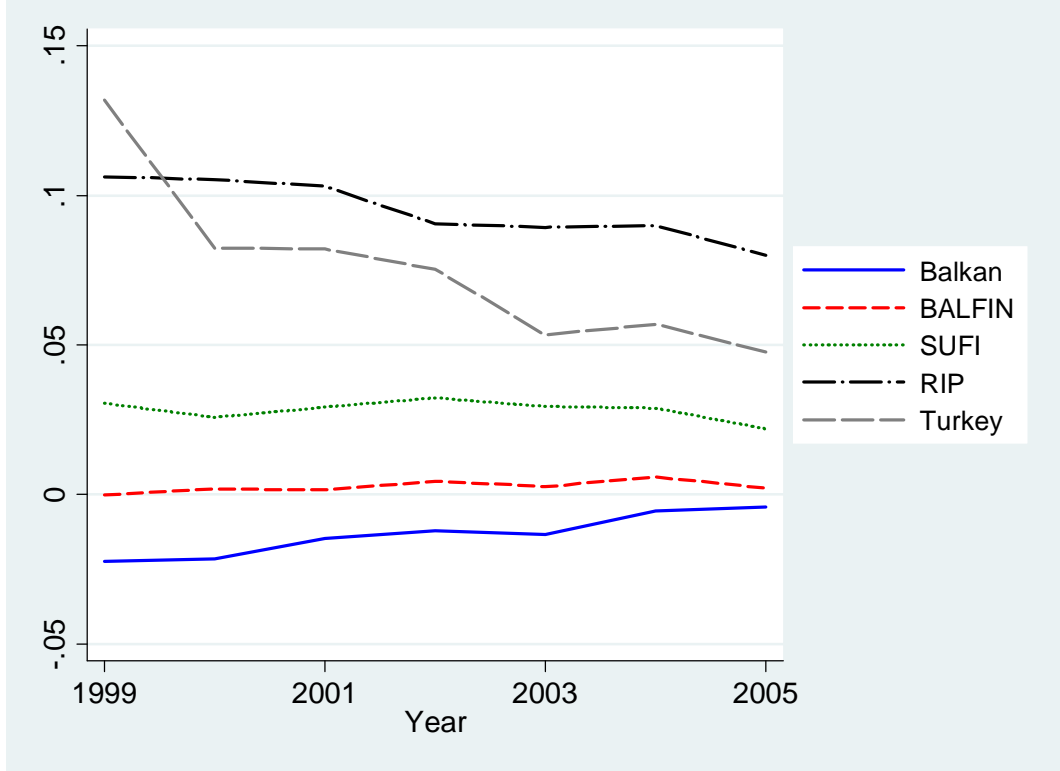

Note: This figure depicts the mean differences in having debt outstanding due to coefficients between the Northerners (excl. Swedes) and other European households. Debt includes all forms of debt (e.g., consumer credits, mortgages), except student loans. The sample period includes 7 years from 1999 to 2005. All decompositions refer to shortfalls relative to Northern households. An additional control variable for income growth expectations is also included in the regressions. Standard errors are computed using 200 bootstrap replications. The country groupings are based on genetic distance (see Notes to Table 1). Source: Author computations using LINDA data from Statistics Sweden. 
Figure 4a: Stockownership: Differences in Participation Rates By Length of Stay in Sweden
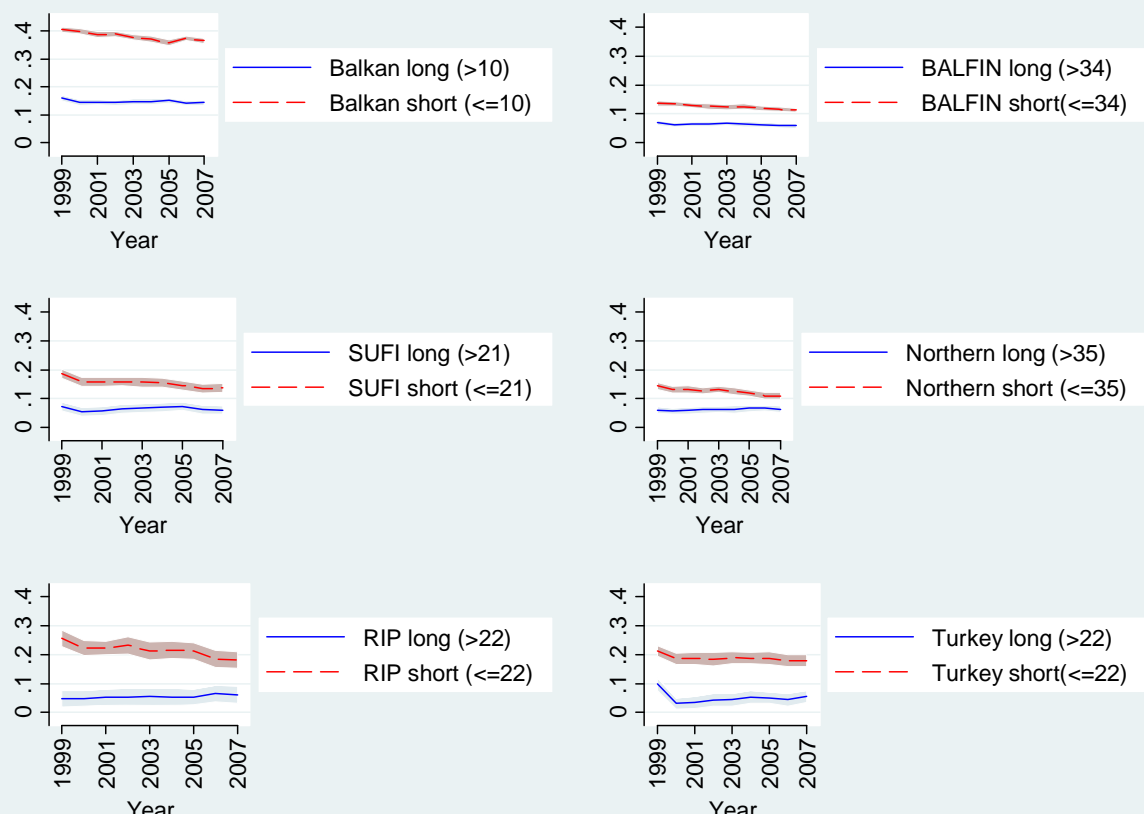

RIP long $(>22)$

RIP short $(<=22)$

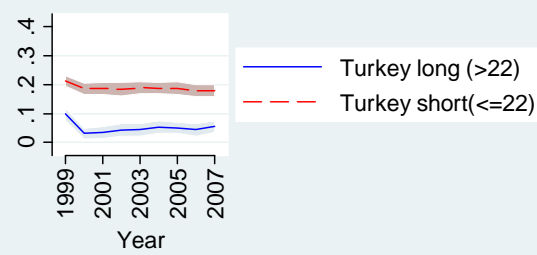

Note: This figure depicts the mean differences in stockownership rates due to coefficients between Swedish and other European households. The Northern group excludes Swedish households. Stocks include all forms of direct and indirectly held stocks, except stocks held through retirement accounts. The sample period includes 9 years from 1999 to 2007. All decompositions refer to differences with respect to Sweden. We divide up the households in each group into two subgroups based on their length of stay in Sweden. Long stays are defined as those above the median number of years in Sweden for the relevant county group; Short stays are those below the median number for the group. The numbers in the parentheses represent the median value for the length of stay in Sweden for the immigrant households in each cultural group as of year 2003. Standard errors are computed using 200 bootstrap replications. The country groupings are based on genetic distance (see Notes to Table 1). Source: Author computations using LINDA data from Statistics Sweden.

\section{Figure 4b: Having Debt Outstanding: Differences in Participation By Length of Stay in Sweden}
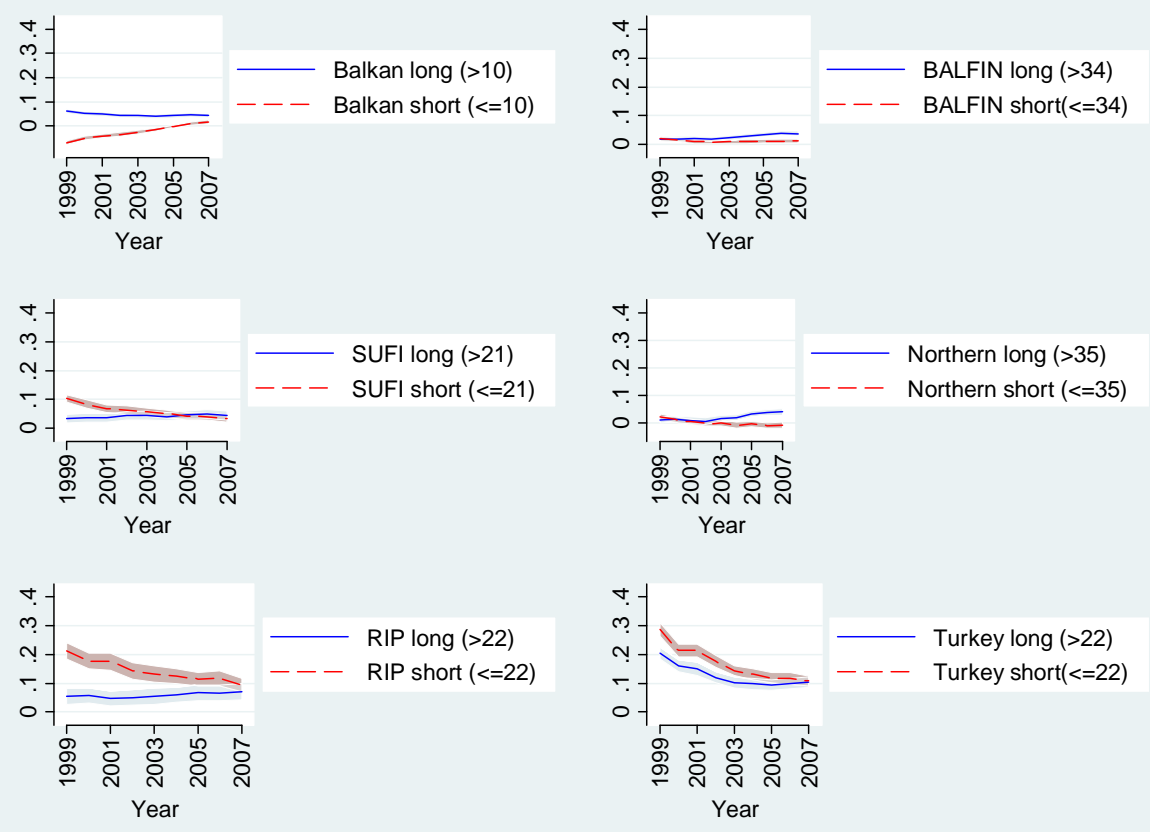

Note: This figure depicts the mean differences in having debt outstanding due to coefficients between Swedish and other European households. The Northern group excludes Swedish households. Debt includes all forms of debt, except student loans. See Notes to Figure 8 a for further details about methodological specifications. 
Figure 4c: Homeownership: Differences in Participation Rates By Length of Stay in Sweden
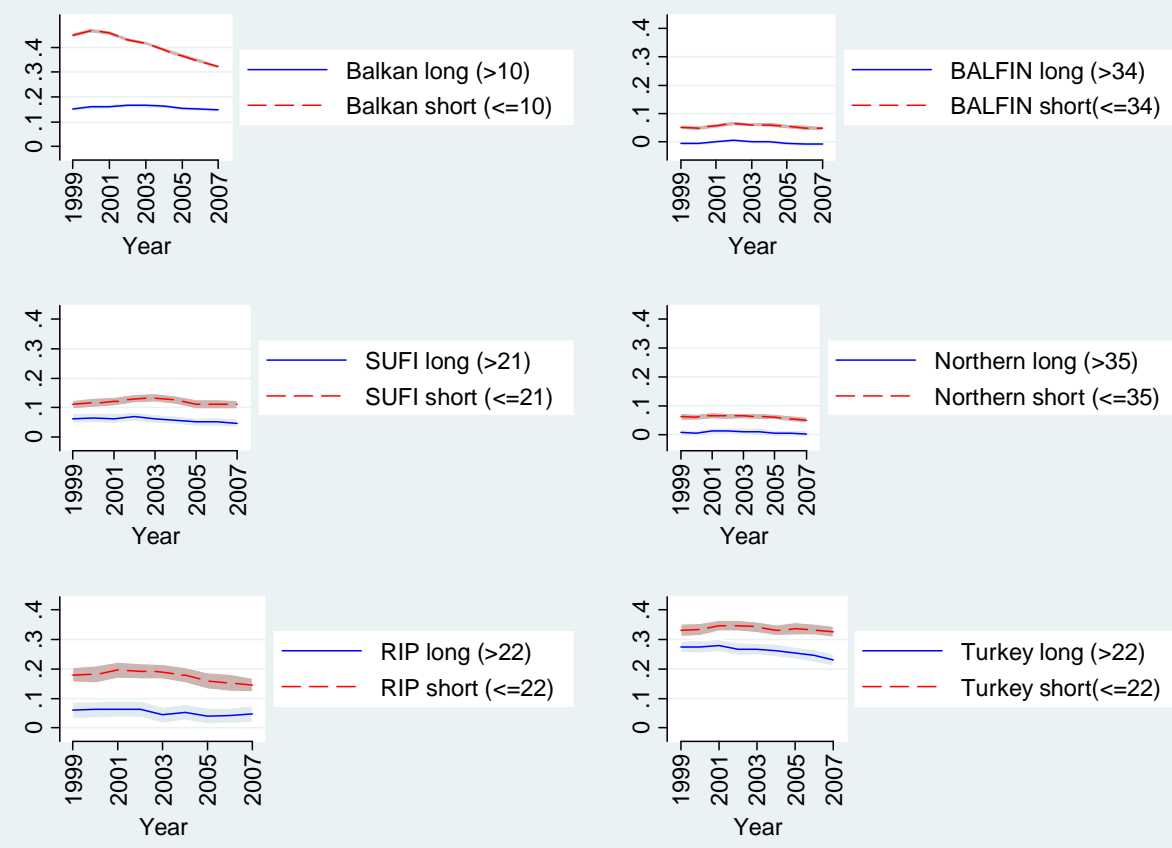

Note: This figure depicts the mean differences in homeownership rates due to coefficients between Swedish and other European households. The Northern group excludes Swedish households. Homeownership includes both single-dwelling houses and tenantowner dwellings. See Notes to Figure 8a for further details.

\section{Figure 5a: Stockownership: Differences in Participation - Age at Immigration}
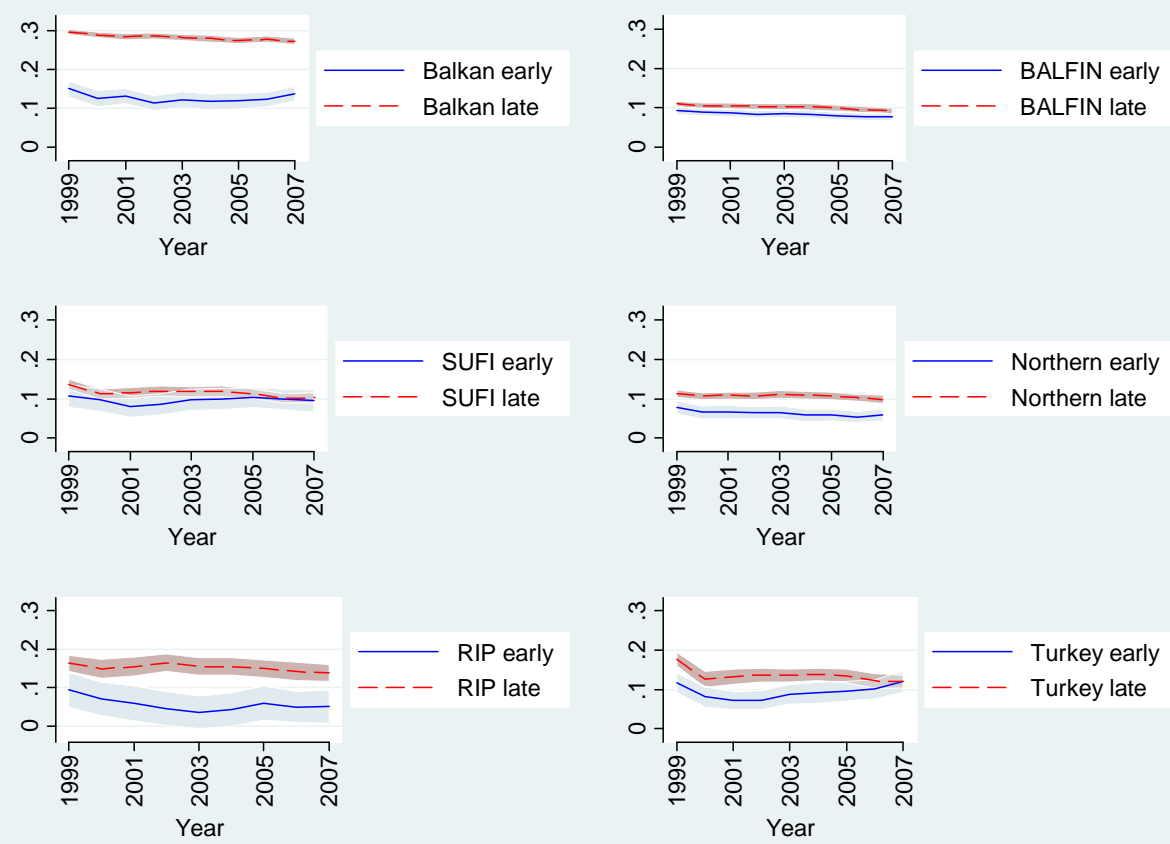

Note: This figure depicts the mean differences in stockownership rates due to coefficients between Swedish and other European households. The Northern group excludes Swedish households. Stocks include all forms of direct and indirectly held stocks, except stocks held through retirement accounts. The sample period includes 9 years from 1999 to 2007 . All decompositions refer to differences with respect to Sweden. We divide up the households in each group into two subgroups based on their age at immigration. Early comers are those who arrive in Sweden prior to their $18^{\text {th }}$ year; late comers are those who arrive after their $18^{\text {th }}$ year. Standard errors are computed using 200 bootstrap replications. See Notes to Table 1 for further details. 
Figure 5b: Having Debt Outstanding: Differences in Participation Rates- Age at Immigration
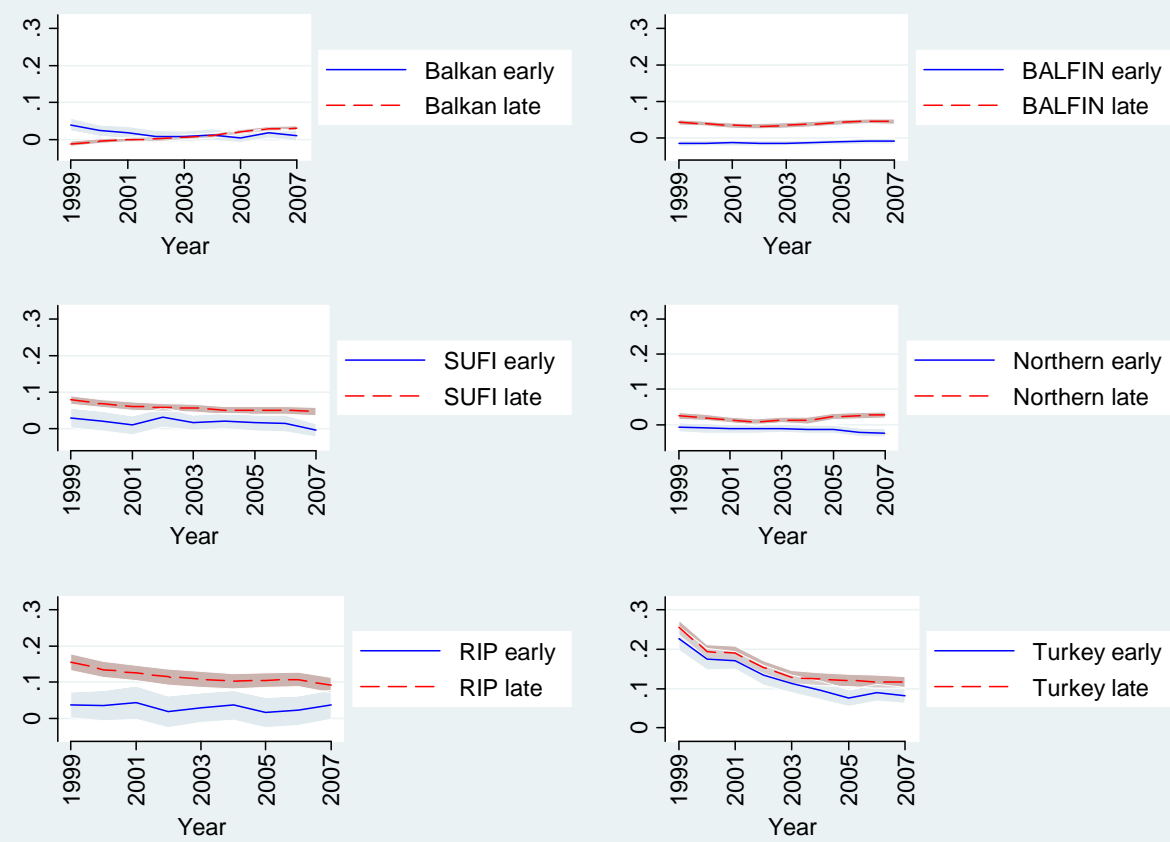

Note: This figure depicts the mean differences in having debt outstanding due to coefficients between Swedish and other European households. The Northern group excludes Swedish households. Debt includes all forms of debt, except student loans. See Notes to Figure 9a for further details.

\section{Figure 5c: Homeownership: Differences in Participation Rates- Age at Immigration}
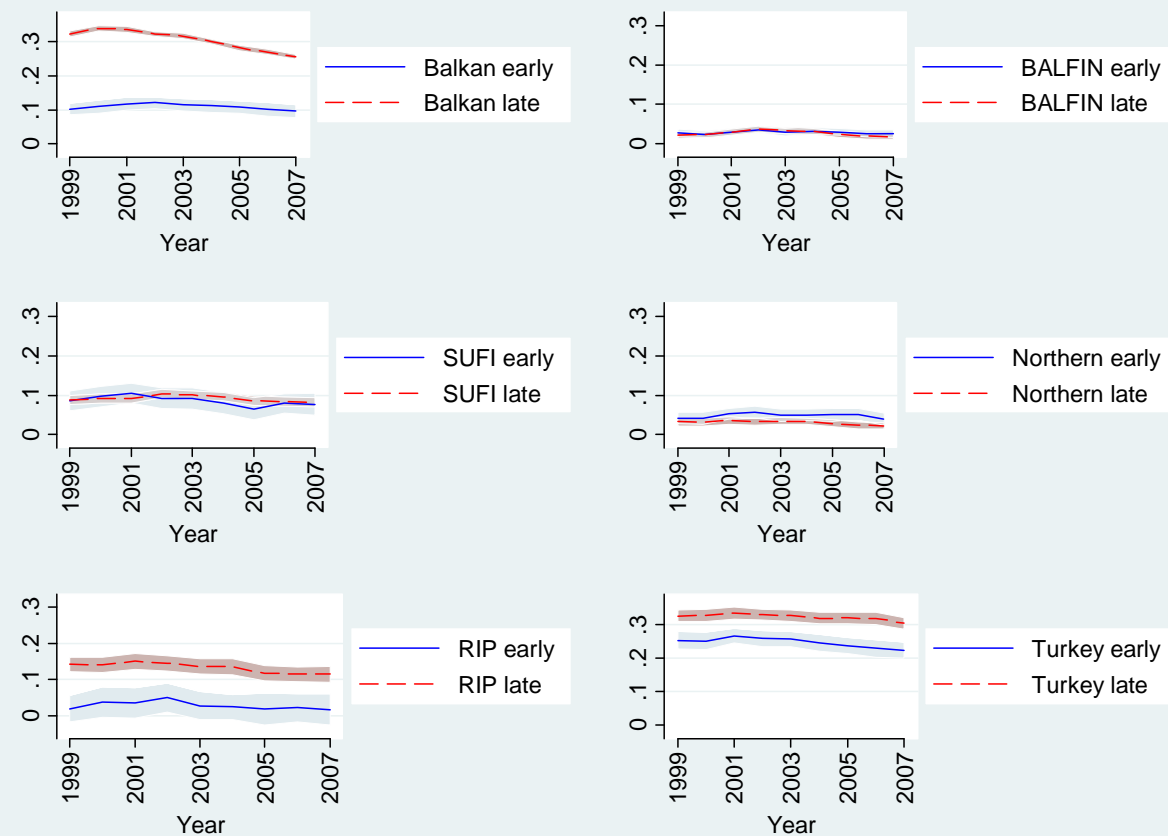

Note: This figure depicts the mean differences in homeownership rates due to coefficients between Swedish and other European households. The Northern group excludes Swedish households. Homeownership includes both single-dwelling houses and tenantowner dwellings. See Notes to Figure 9a for further details. 
Figure 6a: Stockownership: Role of Formal Institutions and Length of Stay
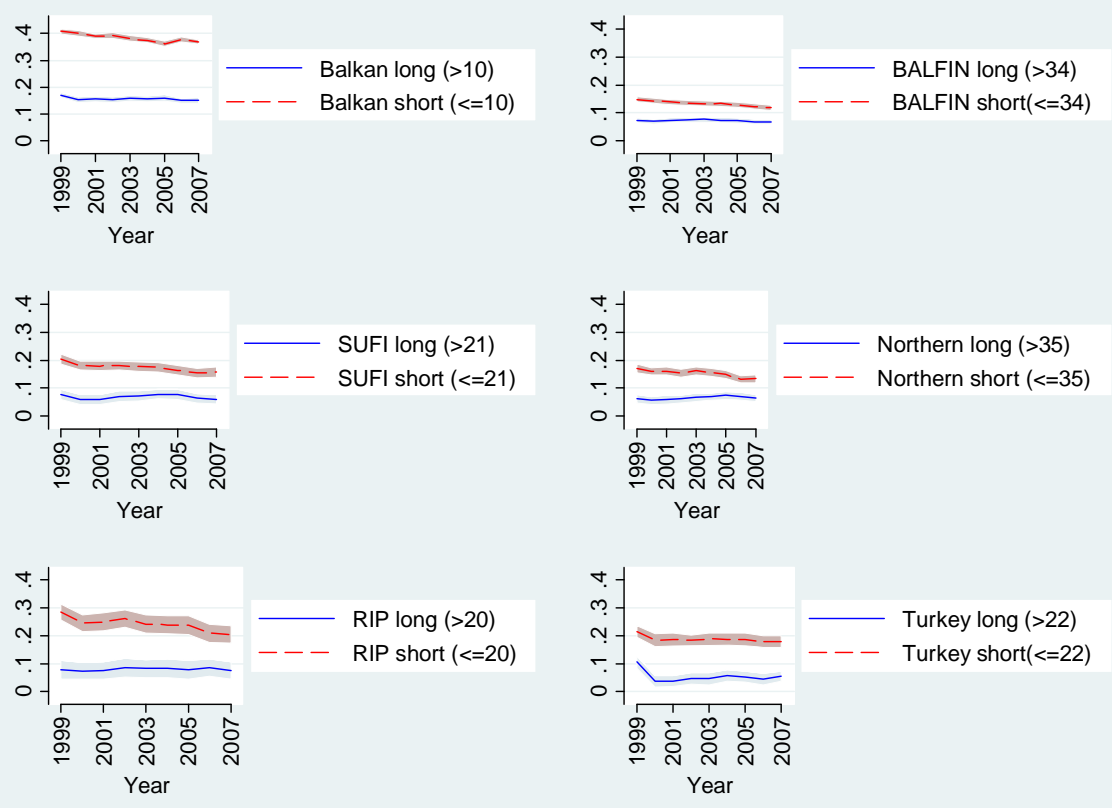

Note: This figure depicts the mean differences in stockownership rates due to coefficients between Swedish and other European households, excluding immigrant households where the spouse of the household head was born in Sweden and has Swedish citizenship. This allows us to focus on those less likely to have intense exposure to informal parts of Swedish culture. The Northern group excludes Swedish households. Stocks include all forms of direct and indirectly held stocks, except stocks held through retirement accounts. All decompositions refer to differences with respect to Sweden. We divide up the households in each group into two subgroups based on their length of stay in Sweden. Long stays are defined as those above the median number of years in Sweden for the relevant county group; Short stays are those below the median number for the group. The numbers in the parentheses represent the median value for the length of stay in Sweden for the immigrant households in each cultural group as of year 2003. Standard errors are computed using 200 bootstrap replications. The country groupings are based on genetic distance (see Notes to Table 1).

\section{Figure 6b: Having Debt Outstanding: Role of Formal Institutions and Length of Stay}

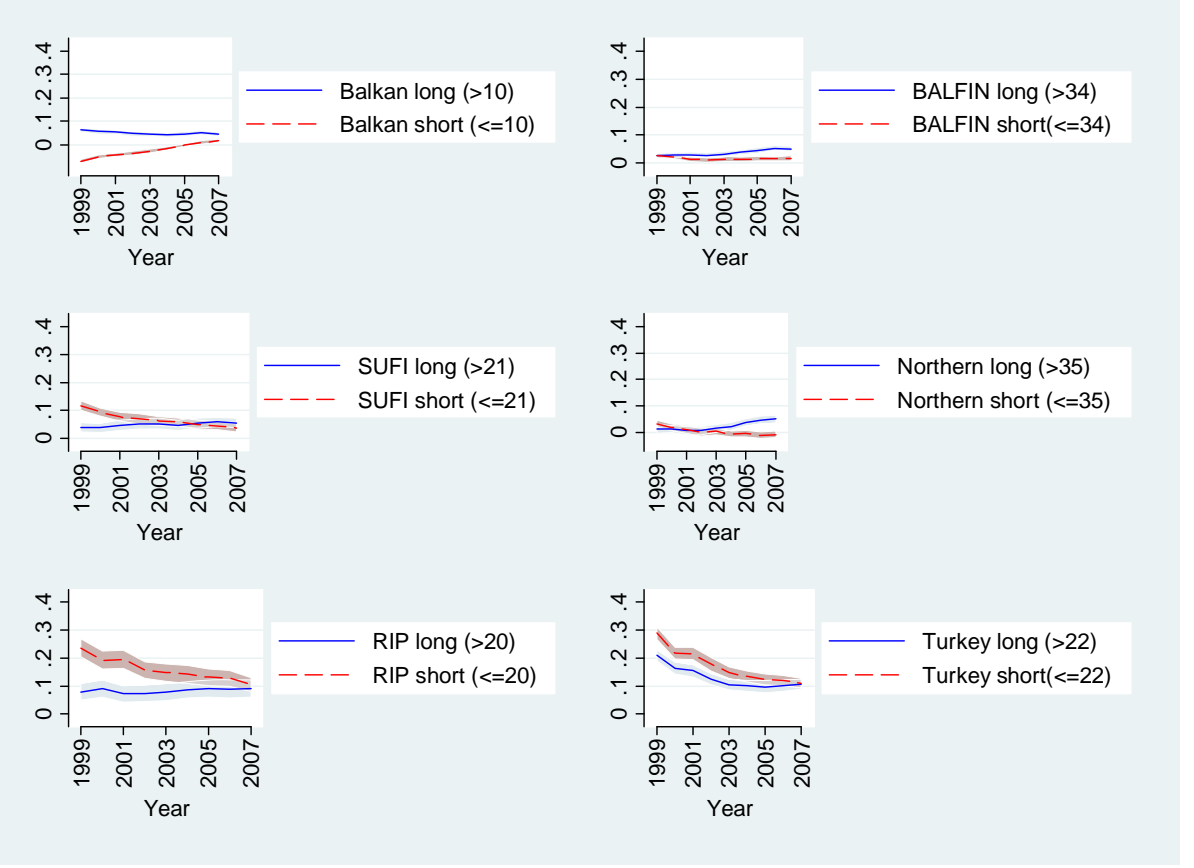

Note: This figure depicts the mean differences in having debt outstanding due to coefficients between Swedish and other European households, excluding immigrant households where the spouse of the household head was born in Sweden and has Swedish citizenship. The Northern group excludes Swedish households. Debt includes all forms of debt, except student loans. See Notes to Figure 10a for further details. 
Figure 6c: Homeownership: Role of Formal Institutions and Length of Stay
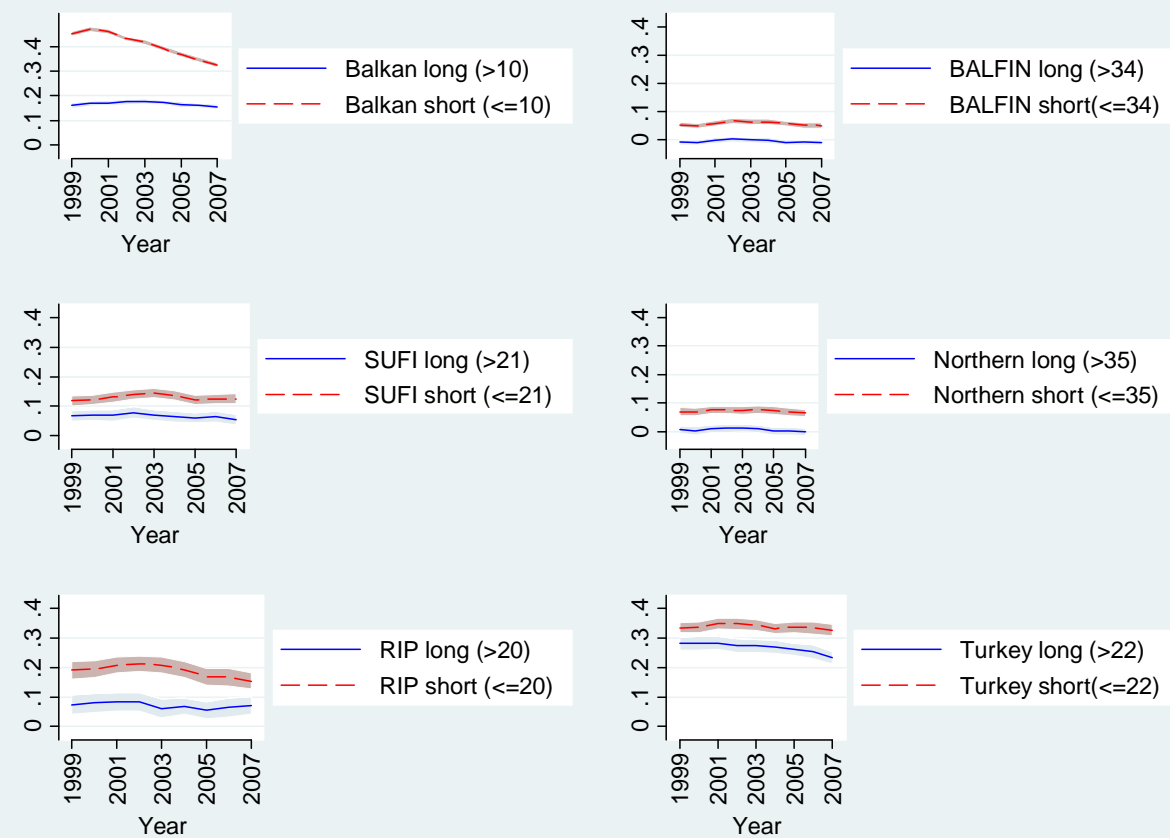

Note: This figure depicts the mean differences in homeownership rates due to coefficients between Swedish and other European households, excluding immigrant households where the spouse of the household head was born in Sweden and has Swedish citizenship. Homeownership includes both single-dwelling houses and tenant-owner dwellings. See Notes to Figure 10a for further details. 


\section{Earlier Working Papers:}

For a complete list of Working Papers published by Sveriges Riksbank, see www.riksbank.se

Estimation of an Adaptive Stock Market Model with Heterogeneous Agents

Some Further Evidence on Interest-Rate Smoothing: The Role of Measurement Errors in the Output Gap

by Mikael Apel and Per Jansson

Bayesian Estimation of an Open Economy DSGE Model with Incomplete Pass-Through

by Malin Adolfson, Stefan Laséen, Jesper Lindé and Mattias Villani

Are Constant Interest Rate Forecasts Modest Interventions? Evidence from an Estimated Open Economy

DSGE Model of the Euro Area

by Malin Adolfson, Stefan Laséen, Jesper Lindé and Mattias Villani

Inference in Vector Autoregressive Models with an Informative Prior on the Steady State

by Mattias Villani

Bank Mergers, Competition and Liquidity

2005:182

by Elena Carletti, Philipp Hartmann and Giancarlo Spagnolo

Testing Near-Rationality using Detailed Survey Data

by Michael F. Bryan and Stefan Palmqvist

Exploring Interactions between Real Activity and the Financial Stance

2005:184

by Tor Jacobson, Jesper Lindé and Kasper Roszbach

Two-Sided Network Effects, Bank Interchange Fees, and the Allocation of Fixed Costs

2005:185

by Mats $A$. Bergman

Trade Deficits in the Baltic States: How Long Will the Party Last?

2005:186

by Rudolfs Bems and Kristian Jönsson

Real Exchange Rate and Consumption Fluctuations follwing Trade Liberalization

by Kristian Jönsson

Modern Forecasting Models in Action: Improving Macroeconomic Analyses at Central Banks

by Malin Adolfson, Michael K. Andersson, Jesper Lindé, Mattias Villani and Anders Vredin

Bayesian Inference of General Linear Restrictions on the Cointegration Space

2005:189

by Mattias Villani

Forecasting Performance of an Open Economy Dynamic Stochastic General Equilibrium Model

$2005: 190$

by Malin Adolfson, Stefan Laséen, Jesper Lindé and Mattias Villani

Forecast Combination and Model Averaging using Predictive Measures

2005:191

by Jana Eklund and Sune Karlsson

Swedish Intervention and the Krona Float, 1993-2002

2006:192

by Owen F. Humpage and Javiera Ragnartz

A Simultaneous Model of the Swedish Krona, the US Dollar and the Euro

2006:193

by Hans Lindblad and Peter Sellin

Testing Theories of Job Creation: Does Supply Create Its Own Demand?

2006:194

by Mikael Carlsson, Stefan Eriksson and Nils Gottfries

Down or Out: Assessing The Welfare Costs of Household Investment Mistakes

2006:195

by Laurent E. Calvet, John Y. Campbell and Paolo Sodini

Efficient Bayesian Inference for Multiple Change-Point and Mixture Innovation Models

2006:196

by Paolo Giordani and Robert Kohn

Derivation and Estimation of a New Keynesian Phillips Curve in a Small Open Economy

2006:197

by Karolina Holmberg

Technology Shocks and the Labour-Input Response: Evidence from Firm-Level Data

2006:198

by Mikael Carlsson and Jon Smedsaas

Monetary Policy and Staggered Wage Bargaining when Prices are Sticky

2006:199

by Mikael Carlsson and Andreas Westermark

The Swedish External Position and the Krona

by Philip R. Lane 
Using a New Open Economy Macroeconomics model to make real nominal exchange rate forecasts 
Evaluating Microfoundations for Aggregate Price Rigidities: Evidence from Matched Firm-Level Data on

Flexible Modeling of Conditional Distributions Using Smooth Mixtures of Asymmetric

Student T Densities

by Feng Li, Mattias Villani and Robert Kohn

Forecasting Macroeconomic Time Series with Locally Adaptive Signal Extraction

Risk Premiums and Macroeconomic Dynamics in a Heterogeneous Agent Model by Ferre De Graeve, Maarten Dossche, Marina Emiris, Henri Sneessens and Raf Wouters

Picking the Brains of MPC Members

by Mikael Apel, Carl Andreas Claussen and Petra Lennartsdotter

Involuntary Unemployment and the Business Cycle

by Lawrence J. Christiano, Mathias Trabandt and Karl Walentin

Housing collateral and the monetary transmission mechanism

by Karl Walentin and Peter Sellin

The Discursive Dilemma in Monetary Policy

by Carl Andreas Claussen and Øistein Røisland

Monetary Regime Change and Business Cycles

Bayesian Inference in Structural Second-Price common Value Auctions

by Bertil Wegmann and Mattias Villani

Equilibrium asset prices and the wealth distribution with inattentive consumers

by Luca Sala, Ulf Söderström and Antonella Trigari

Density-Conditional Forecasts in Dynamic Multivariate Models

by Michael K. Andersson, Stefan Palmqvist and Daniel F. Waggoner

Anticipated Alternative Policy-Rate Paths in Policy Simulations

by Stefan Laséen and Lars E. O. Svensson

MOSES: Model of Swedish Economic Studies

by Gunnar Bårdsen, Ard den Reijer, Patrik Jonasson and Ragnar Nymoen

The Effects of Endogenuos Firm Exit on Business Cycle Dynamics and Optimal Fiscal Policy

by Lauri Vilmi

Parameter Identification in a Estimated New Keynesian Open Economy Model 
The Cost of Consumer Payments in Sweden

by Björn Segendorf and Thomas Jansson

Trade Credit and the Propagation of Corporate Failure: An Empirical Analysis

by Tor Jacobson and Erik von Schedvin

Structural and Cyclical Forces in the Labor Market During the Great Recession: Cross-Country Evidence

by Luca Sala, Ulf Söderström and AntonellaTrigari

Pension Wealth and Household Savings in Europe: Evidence from SHARELIFE

by Rob Alessie, Viola Angelini and Peter van Santen

Long-Term Relationship Bargaining

by Andreas Westermark

Using Financial Markets To Estimate the Macro Effects of Monetary Policy: An Impact-Identified FAVAR*

by Stefan Pitschner

DYNAMIC MIXTURE-OF-EXPERTS MODELS FOR LONGITUDINAL AND DISCRETE-TIME SURVIVAL DATA

by Matias Quiroz and Mattias Villani

Conditional euro area sovereign default risk

by André Lucas, Bernd Schwaab and Xin Zhang

Nominal GDP Targeting and the Zero Lower Bound: Should We Abandon Inflation Targeting?*

by Roberto M. Billi

Un-truncating VARs*

by Ferre De Graeve and Andreas Westermark

Housing Choices and Labor Income Risk

by Thomas Jansson

Identifying Fiscal Inflation*

by Ferre De Graeve and Virginia Queijo von Heideken

On the Redistributive Effects of Inflation: an International Perspective*

by Paola Boel

Business Cycle Implications of Mortgage Spreads* 
Firm-Level Evidence of Shifts in the Supply of Credit 2013:280 by Karolina Holmberg

Lines of Credit and Investment: Firm-Level Evidence of Real Effects of the Financial Crisis by Karolina Holmberg

A wake-up call: information contagion and strategic uncertainty

by Toni Ahnert and Christoph Bertsch

Debt Dynamics and Monetary Policy: A Note

by Stefan Laséen and Ingvar Strid

Optimal taxation with home production

2014:284

by Conny Olovsson 
Sveriges Riksbank

Visiting address: Brunkebergs torg 11

Mail address: se-103 37 Stockholm

Website: www.riksbank.se

SVERIGES Telephone: +468 78700 00, Fax: +46 8210531

RIKSBANK E-mail: registratorn@riksbank.se 